\title{
Impact of lightning on the lower ionosphere of Saturn and possible generation of halos and sprites
}

\author{
D. Dubrovin ${ }^{\mathrm{a}, *}$, A. Luque ${ }^{\mathrm{b}}$, F.J. Gordillo-Vazquez ${ }^{\mathrm{b}}$, Y. Yair ${ }^{\mathrm{c}}$, F.C. Parra-Rojas ${ }^{\mathrm{b}}$, U. Ebert $^{\mathrm{d}}$, C. Price ${ }^{\mathrm{a}}$ \\ ${ }^{a}$ Department of Geophysical, Atmospheric and Planetary Sciences, Tel-Aviv University, Israel \\ ${ }^{\mathrm{b}}$ Institute for Astrophysics of Andalusia (IAA-CSIC), Granada, Spain \\ ${ }^{\mathrm{c}}$ Department of Life and Natural Sciences, The Open University of Israel, Ra'anana, Israel \\ ${ }^{\mathrm{d}}$ Centrum Wiskunde E Informatica (CWI), Amsterdam, The Netherlands
}

\section{A R T I C L E I N F O}

\section{Article history:}

Received 22 December 2013

Revised 18 June 2014

Accepted 24 June 2014

Available online 3 July 2014

\section{Keywords:}

Saturn

Lightning

Ionospheres

\begin{abstract}
A B S T R A C T
We study the effect of lightning on the lower ionosphere of Saturn. A self-consistent one-dimensional model of the electric field and electron density is used to estimate the changes of the local electron and photon emissions. The chemical fingerprint and ion densities are determined using a detailed selfconsistent kinetic model. Charge moment change, depth of lightning flashes and their duration are estimated based on the known constraints of saturnian lightning activity. We test two electron density profiles and find that the conservative estimation of lightning charge moment change $10^{4}$ to $10^{5} \mathrm{C} \mathrm{km}$ could lead to faint halos and possibly sprites if the base of the ionosphere is located at $1000 \mathrm{~km}$ above the $1 \mathrm{bar}$ level; if the base of the ionosphere is located at $600 \mathrm{~km}$ then only the extreme scenario of a $10^{6} \mathrm{C} \mathrm{km}$ charge moment change could induce considerable ionization, halos and possibly sprites. We found that $\mathrm{H}_{3}^{+}$ions are rapidly produced from the parent $\mathrm{H}_{2}^{+}$ions through the fast reaction $\mathrm{H}_{2}^{+}+\mathrm{H}_{2} \rightarrow \mathrm{H}_{3}^{+}+\mathrm{H}$, so that $\mathrm{H}_{3}^{+}$becomes the dominant ion in all the scenarios considered. The resulting light emissions, mostly in the blue and ultraviolet spectral regions, are below the detection threshold of Cassini.
\end{abstract}

(c) 2014 Elsevier Inc. All rights reserved.

\section{Introduction}

Lightning has been observed on several planets in the Solar System, and indirectly inferred on others (most recently reviewed in Yair (2012)). On the gas giants Jupiter and Saturn lightning activity is concentrated in thunderstorms with large physical dimensions, which exhibit vigorous convection and associated cloud systems. The existence of lightning flashes on Saturn was inferred from multiple observations of high frequency radio signals, known as Saturn Electrostatic Discharges (SED) (see review by Fischer et al. (2008)), as well as from optical observations by the Cassini spacecraft (Dyudina et al., 2010, 2013). The most recent storm on Saturn, which started early December 2010 and lasted almost a year, was exceptionally active (Fischer et al., 2011; Dyudina et al., 2013); lightning activity persisted for 9 months (Sayanagi et al., 2013). Lightning storms on Saturn are rare and are found at specific latitudes, many of them around $35^{\circ}$ in both hemispheres. They typically occur in the respective hemisphere's summer.

Lightning activity on Earth is accompanied by transient luminous events (TLE) in the mesosphere above the thunderclouds

\footnotetext{
* Corresponding author.

E-mail addresses: Daria.Dubrovin@openu.ac.il, Daria.Dubrovin@gmail.com (D. Dubrovin).
}

(Pasko et al., 2012). TLE is an inclusive term which describes the electric breakdown in the mesosphere induced by a quasi-electrostatic field (sprites and halos), and the illumination of the lower ionosphere by the lightning electro-magnetic pulse (elves), as well as other phenomena. In this paper our focus is the quasi-electrostatic discharges that may include a visible diffuse region (a halo) and a lower filamentary region, which is commonly known as sprite. Our analysis deals with the formation of halos and sprites.

Sprites are observed mainly at night-time in the altitude range of $40-90 \mathrm{~km}$, below the ionosphere. According to the commonly accepted model of sprite formation on Earth, they form as a result of the quasi-electrostatic field (QES) due to a charge moment change (CMC) in the thundercloud. The induced electric field will cause rapid growth in the electron density if it is strong enough. Eventually the electric field will be screened by the free electrons, and the process will stop. This process is accompanied by the excitation of molecules and optical emissions, perceived as an upward propagating visible halo, a diffuse brightening of Earth's upper mesosphere. The chemical influence of halos in the upper atmosphere of the Earth between $50 \mathrm{~km}$ and $85 \mathrm{~km}$ has been recently modeled by Parra-Rojas et al. (2013). The halo is sometimes followed by bright tendrils at lower altitudes, similar to streamer discharges at standard pressure. For a comprehensive review of TLE 
physics and their chemical effects we refer the reader to Pasko et al. (2012).

The existence of powerful lightning discharges in other planetary atmospheres led Yair et al. (2009) to examine whether sprites can form in extra-terrestrial atmospheres, by analogy with the processes occurring on Earth. The conventional view on the occurrence conditions of discharges above terrestrial thunderclouds goes back to Wilson (1925). While the ionosphere is highly conducting and therefore rapidly screens the suddenly changing electric field above a lightning stroke, the electric field can exceed the classical break-down field in the low conductivity region of the night time terrestrial mesosphere, creating electric breakdown, in the form of halos and sprites. Yair et al. (2009) compared the electric field induced by various charge configurations with the local conventional breakdown field $E_{k}$, as calculated by Sentman (2004) for the respective atmospheric compositions. This approach, however, neglects the finite conductivity in the weakly ionized atmosphere below the ionosphere.

In this paper we examine the response of Saturn's ionosphere to the lightning flashes in the water-ice clouds. The paper is organized as follows: In Section 2 we describe the known constraints on the lightning discharge, and derive possible CMC values and flash duration. In Section 3 we discuss the electron density at the bottom side of Saturn's ionosphere. In Section 4 we examine the response of the atmosphere at various altitudes to an externally applied electric field, taking the local conductivity into account. We find that $E>E_{k}$ is not always a sufficient criterion to predict whether the local electron density is affected. In Section 5 the self-consistent zero-dimensional model of Luque and GordilloVázquez (2011) is used to estimate the change in electron density due to the flash, and the optical features of the event. In Section 6 a detailed self-consistent kinetic model of the reactions taking place in the perturbed saturnian atmosphere (Gordillo-Vázquez, 2008, 2010) is used to estimate the chemical fingerprint and optical emissions of the event.

\section{Lightning on Saturn}

\subsection{Lightning energy}

The simulation of TLEs on Saturn requires some assumptions concerning the electric field applied by the lightning flash. We need to know the amount of charge neutralized by the lightning flash, and the duration of the stroke. The average total energy dissipated by a lightning discharge is estimated at $10^{12}$ to $10^{13} \mathrm{~J}$, based on SED and optical observations (Fischer et al., 2007, 2006; Dyudina et al., 2010, 2013). According to Dyudina et al. (2010) the observed lightning flashes are three orders of magnitude stronger than the median terrestrial lightning and comparable with terrestrial super-bolts. In Fischer et al. (2006) and elsewhere it was assumed that the duration of the lightning discharge is similar to Earth's intra-cloud (IC) discharges, several 10-s of microseconds (values for terrestrial lightning can be found in Uman (2001, p. 124)). Farrell et al. (2007) suggested that a faster discharge ( $\sim 1 \mu \mathrm{s})$ would fit the observed SED frequency spectrum better, implying significantly lower energies $\left(\sim 10^{9} \mathrm{~J}\right)$, comparable with typical terrestrial lightning energies. The optical observations by Dyudina et al. $(2010,2013)$ provide an independent confirmation of the high energy super-bolt like scenario (G. Fischer, personal communication).

\subsection{Lightning current and electric field}

In this work we follow the high energy scenario suggested by Fischer et al. (2006) and described by Farrell et al. (2007), where the current flowing through the lightning channel follows a biexponential function of the form

$I(t)=I_{0}\left(\exp \left(-t / \tau_{1}\right)-\exp \left(-t / \tau_{2}\right)\right)$,

where $\tau_{2}$ represents the rise time of the current wave, and is typically 10 times faster than the overall duration of the stroke, represented by $\tau_{1}$.

The lightning flash is located almost $1000 \mathrm{~km}$ below the region of interest (the lower ionosphere between 400 and $900 \mathrm{~km}$ above the 1 bar level). At these length scales the full electric field has to be considered. At small angles relative to a vertically oriented dipole-like discharge the vertical component of the electric field $E_{p}$ is dominated by the quasi-electrostatic (QES) and the induction fields (Bruce and Golde, 1941),

$E_{p}(z, t)=\frac{1}{\pi \epsilon_{0}}\left(\frac{1}{\left(z-z_{p}\right)^{3}} M\left(t-\left(z-z_{p}\right) / c\right)+\frac{1}{c\left(z-z_{p}\right)^{2}} \frac{d}{d t} M\left(t-\left(z-z_{p}\right) / c\right)\right)$,

where $M(t)$ is the charge moment change, $z$ is the altitude where the field is measured and $z_{p}$ is the altitude of the center of the dipole, $\epsilon_{0}$ is the permittivity of vacuum, and $c$ is the speed of light. The two terms in Eq. (2) are the QES field and the induction field, respectively. The far field (EMP) component can be neglected at small angles. While the QES component dominates the electric field above the lightning flash on Earth, justifying the commonly used QES heating model of sprites, we find that on Saturn the induction component dominates. An example of the induced electric field on Saturn and on Earth is plotted in Fig. 1.

The induction component of the field rises and decays with the current, Eq. (1), reaching a maximum value on the time scale of the current rise time $\tau_{2}$; the QES component reaches a constant value $M /\left(z-z_{p}\right)^{3}$ after the current has decayed, on the time scale of the flash duration $\tau_{1}$, and then decays on the time scale of the local Maxwell relaxation time, as will be discussed in Section 4. The induction component is stronger than the QES component, and it is applied faster, as a result it may significantly increase the local
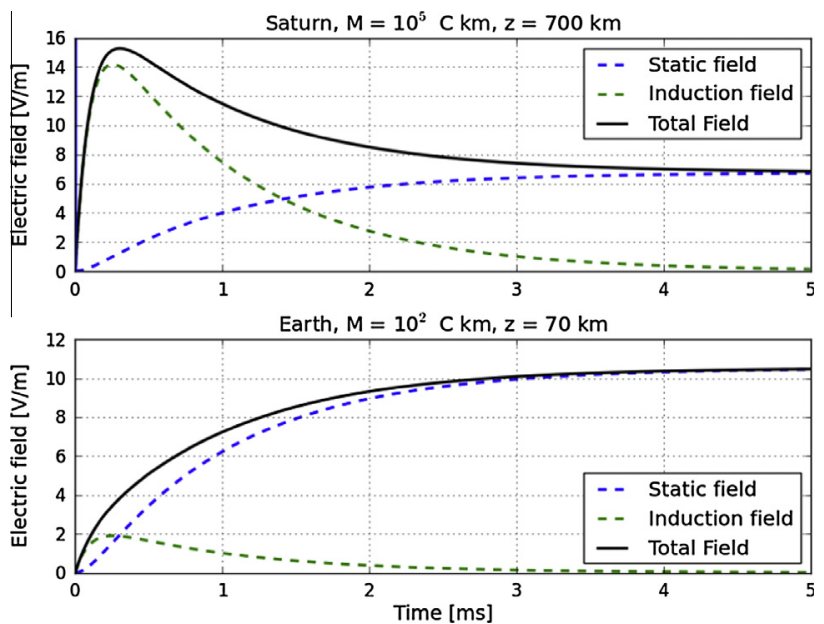

Fig. 1. Top: The time evolution of the applied electric field at $700 \mathrm{~km}$ above the 1 bar level due to a stroke with a charge moment change of $M=10^{5} \mathrm{C} \mathrm{km}$ located at $-110 \mathrm{~km}$ below the 1 bar level. The current follows Eq. (1). The static (blue) and induction (green) components, and the total electric field (black), are calculated according to Eq. (2). The induction field reaches its maximum before the static field does, and then decays. Bottom: The applied electric field due to a cloud to ground flash on Earth induced by a charge moment change of $M=10^{2} \mathrm{C} \mathrm{km}$, calculated at $70 \mathrm{~km}$ above ground. The center of the dipole is at $0 \mathrm{~km}$. The induction component is weaker than the static component. (For interpretation of the references to color in this figure legend, the reader is referred to the web version of this article.) 
electron density, decreasing the local Maxwell time and causing very fast screening of the QES component. This happens if the characteristic ionization time is shorter than the duration of the induction field, so that the induction field has enough time to considerably increase the electron density. This point is discussed further in Section 4.

\subsection{Charge separation and charge moment change}

The charge moment change (CMC) is commonly defined for terrestrial lightning as the product of the amount of charge and the height from which it was lowered to the ground (e.g. Bruce and Golde, 1941). On Saturn we define $M(t)=Q(t) a / 2$, where $a$ is the vertical separation of the charge cell centers, and $Q(t)=\int_{0}^{t} I\left(t^{\prime}\right) d t^{\prime}$. The current $I(t)$ is defined in Eq. (1).

The storm clouds on Saturn are larger than on Earth, towering more than a hundred kilometers. However we do not know what is the extent of the charge separation. Yair et al. (1995) modeled the charging process in clouds on Jupiter and found that the charge separation corresponds with a lightning channel of $20 \mathrm{~km}$. They also found that updraft in the developing stage is $\sim 50 \mathrm{~m} / \mathrm{s}$. The clouds on Saturn are larger than on Jupiter, with stronger updrafts $(\sim 150 \mathrm{~m} / \mathrm{s}$, Sánchez-Lavega et al., 2011), therefore we can assume that a lightning channel on Saturn spans larger vertical distances, starting from a few tens and up to a hundred kilometers. The typical return stroke propagation speed on Earth is 0.3 of the speed of light, therefore for a $100 \mathrm{~km}$ channel the stroke cannot be shorter than $1 \mathrm{~ms}$. Therefore we set $\tau_{1}=1 \mathrm{~ms}$ and $\tau_{2}=0.1 \mathrm{~ms}$. This means that the electric field in the mesosphere reaches its maximum within $1 \mathrm{~ms}$. If the stroke duration is longer than the local relaxation time, the induced electric field at that altitude would be partially screened before it reached its maximum value, and a sprite is less likely.

We estimate the value of the CMC of Saturn's lightning based on the energy constraints and the physical size of the water ice clouds, assumed to be the lightning source in its atmosphere. The base of these clouds is located at $8-10$ bar, $130-160 \mathrm{~km}$ below the 1 bar level (Atreya, 1986; Atreya and Wong, 2005). During lightning-producing storms the cloud undergoes significant upward development, according to Sánchez-Lavega et al. (2011), reaching as high as the 0.1 bar level, $\sim 90 \mathrm{~km}$ above the 1 bar level. Strong updrafts in the cloud are estimated by Sánchez-Lavega et al. (2011) to reach $150 \mathrm{~m} / \mathrm{s}$. Optical observations by Dyudina et al. $(2010,2013)$ show a circular footprint of the lightning discharge at cloud-top, which allows to locate a point-like light source $125-250 \mathrm{~km}$ below the cloud top, within the water ice clouds. Dyudina et al. (2013) observed lightning flashes on the day-side. In these observations the cloud tops are estimated to be deeper than 1.2 bar.

A vertical channel acts as a multiple point source located at a range of altitudes. Therefore we suggest that for a vertically extended lightning channel the estimations in Dyudina et al. $(2010,2013)$ give the altitude of the lowest portion of the channel, which may extend vertically to higher altitudes. Here we assume that the charge centers are vertically separated by a few tens of kilometers, and up to a hundred kilometers. For this simple configuration we neglect wind shear effect, even though this factor may be important for cloud development and inhibit charge separation. We assume that the lightning channel is located between the base of the water ice cloud at 8-10 bars $(130-160 \mathrm{~km}$ below the 1 bar level) and up to a $100 \mathrm{~km}$ above this altitude.

To estimate the relation between the lightning CMC and the dissipated energy we assume that the removed charge is concentrated within uniformly charged, non-overlapping identical spheres located one above the other, with a radius of a few tens of kilometers at most. The electrostatic energy stored by this configuration is given by:
$U_{p}=\frac{2 Q^{2}}{4 \pi \epsilon_{0}}\left(\frac{3}{5 R}-\frac{1}{2 a}\right)$,

where $Q$ is the total charge within each sphere, $\epsilon_{0}$ is the permittivity of vacuum, $R$ is the radius of the spheres and $a$ is the vertical separation between the sphere centers $(a>2 R)$. In analogy with the accepted definition of the CMC in the cloud-to-ground lightning on Earth, $M=Q a / 2$.

We tested this approach on terrestrial lightning, using data published by Maggio et al. (2009), who reported simultaneous charge distribution and energy measurements of intra-cloud (IC) lightning discharges on Earth. Eq. (3) gives a good estimate of the energy released by IC discharges in the mature stage of the storm. Taking the energy constraint of lightning on Saturn into account, $M(t)$ can be $\sim 10^{4}$ to $10^{5} \mathrm{C} \mathrm{km}$ when charge separation is of the order of a few $10-\mathrm{s} \mathrm{km}$, and it can reach $10^{6} \mathrm{C} \mathrm{km}$ in the extreme scenario where separation is $100 \mathrm{~km}$.

\section{The electron density profile on Saturn}

The ambient electron density in the atmosphere determines the Maxwell relaxation time and the conditions for the onset of an electron avalanche. The electron density profile in planetary atmospheres is measured by means of radio occultation. Kliore et al. (2009) report the results of several radio occultations of Saturn, of which two are mid-latitude dawn profiles, and five are mid-latitude dusk profiles. According to Kliore et al. (2009) the dawn electron density (assumed to be equivalent to the night-time electron density according to Galand et al. (2009)) at $1000 \mathrm{~km}$ is between $10^{2}$ and $10^{3} \mathrm{~cm}^{-3}$, and dusk electron density is about an order of magnitude higher (all altitudes are with respect to the 1 bar pressure level, a common reference for the giant planets). Reliable measurements below $1000 \mathrm{~km}$ are not available (A. Nagy, personal communication).

Moore et al. (2004) modeled Saturn's ionosphere, predicting mid-latitude electron density at $18 \mathrm{~h}$ local time (LT) of $\sim 10^{4} \mathrm{~cm}^{-3}$ at $1300 \mathrm{~km}$, followed by a steep decrease at lower altitudes, and reaching $10^{1} \mathrm{~cm}^{-3}$ at $1000 \mathrm{~km}$. Moore et al. (2004) state that ion and electron densities do not change drastically during the night from that shown for 18 LT. An earlier model by Moses and Bass (2000) placed the base of the ionosphere at $600 \mathrm{~km}$, assuming a photo-ionization of carbo-hydrates between 600 and $1000 \mathrm{~km}$. Galand et al. (2009) extend the model described by Moore et al. (2004) to include the carbo-hydrate layer, predicting a fairly constant night-time ( $6 \mathrm{LT}$ ) electron density $N_{e} \sim 10^{2} \mathrm{~cm}^{-3}$ in the altitude range of $600-1000 \mathrm{~km}$, followed by a steep decrease at lower altitudes. The low altitude electron density at 6 LT is one order of magnitude lower than at 18 LT in this model. None of these results can be compared with observations.

For the purpose of modeling TLEs we need to know the nighttime electron density profile in the lower ionosphere and the region below it, in the altitude range of $200-1000 \mathrm{~km}$. We used two electron densities profiles, based on the models discussed above: profile (a) where we use the model results of Moore et al. (2004) at 6 LT only down to $900 \mathrm{~km}$, to model the absence of a $\mathrm{CH} 4$ layer; and profile (b), where the base of the ionosphere is at $600 \mathrm{~km}$ (Galand et al., 2009, 6 LT down to $600 \mathrm{~km}$ ). The electron density is assumed to decrease exponentially below $900 \mathrm{~km}$ for profile (a) and below $600 \mathrm{~km}$ for profile (b) with scale heights of 30 and $55 \mathrm{~km}$ respectively. In Fig. 2 we show the electron density (panel (a)), and the Maxwell relaxation time (panel (b)). Panel (b) is discussed in more detail in the next section. 

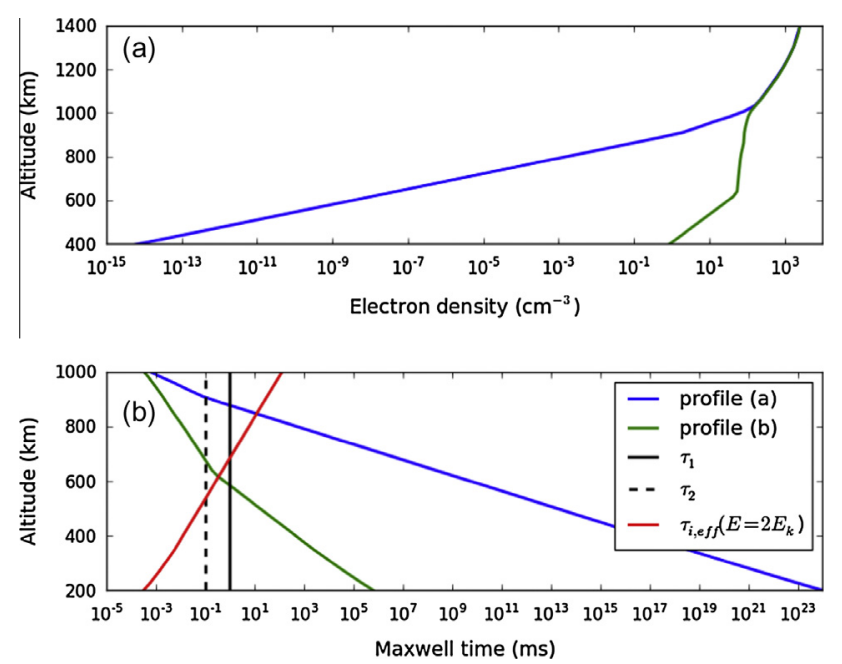

Fig. 2. Panel (a): Night-time electron density for profiles (a) (blue) and profile (b) (green). Panel (b): Maxwell relaxation time according to profile (a) (blue) and profile (b) (green). The decay and rise times of the current are indicated ( $\tau_{1}$ and $\tau_{2}$ from Eq. (1) respectively). The effective ionization time as calculated for the electric field $E=2 E_{k}$ is plotted in red. (For interpretation of the references to color in this figure legend, the reader is referred to the web version of this article.)

\section{Impact of electric fields on the lower ionosphere}

Electric breakdown in the upper atmosphere occurs if the reduced field $E / N$, where $E$ is the field strength and $N$ is the number density of neutral molecules, exceeds the conventional breakdown field at that altitude. The electric field induced by the lightning flash falls of as a power of the altitude $z$ above the lightning flash, while the air density $N$ decays exponentially, approximately as $\exp (-h / H)$, where $H$ is the scale height of the atmosphere and $h$ is the altitude above the reference level (here 1 bar); therefore the reduced electric field $E / N$ increases with altitude. The conventional breakdown field $E_{k}$ is defined by the competition between two opposing processes in the gas: impact ionization of neutrals by accelerated electrons, and attachment of electrons to certain molecules in the gas $\left(\mathrm{O}_{2}\right.$ on Earth, $\mathrm{H}_{2}$ on Saturn). If the lightning induced electric field exceeds $E_{k}$ below the ionosphere then ionization dominates, and electric breakdown can occur. This is the classical condition for the occurrence of sprites.

This approach applies to the part of the atmosphere below a certain altitude that is essentially non-conducting, with a well conducting ionosphere further above. But in practice the atmospheric conductivity does not vanish completely at any altitude, forming a weakly conducting layer of several 10-s of kilometers on Earth, and probably several 100-s of kilometers on Saturn. In this region an electric field is electrically screened from a medium with conductivity $\sigma$ within the Maxwell relaxation time, defined as $\tau_{M}=\epsilon_{0} / \sigma$, where $\epsilon_{0}$ is the electric permittivity of vacuum. Maxwell screening time may be shorter than the time required for creating electron avalanches.

The electric conductivity $\sigma$ is determined by the local electron density $N_{e}$ and the neutral density $N, \sigma=e \mu_{e} N_{e}$. The electron mobility $\mu_{e}$ depends on the electric field and scales as $1 / N$. As the local electron density increases, $\tau_{M}$ decreases respectively. The implications for terrestrial sprites were discussed in many papers, e.g. Pasko et al. (1998), Pasko and Stenbaek-Nielsen (2002), Qin et al. (2011), and Sun et al. (2013). It is possible to distinguish between a weakly conducting region, where the lightning flash induces a descending ionization wave-front, which can be visible in the form of a halo; and an essentially non-conducting region where sprites can form (Pasko et al., 1998; Pasko and Stenbaek-Nielsen, 2002). Sun et al. (2013) introduce the ionization screening time as a generalization of the Maxwell time for ionizable media where the electron density and conductivity change during the electric screening process.

The attachment process in the hydrogen dominated atmosphere of Saturn, and other Gas Giants is inefficient (see e.g. Celiberto et al., 2001; Yoon et al., 2008). This means that the conventional electric breakdown field is low, $E_{k} \sim 46 \mathrm{Td}\left(1 \mathrm{Td}=10^{-17} \mathrm{~V} \mathrm{~cm}^{2}\right)$. As a result, even if the electric field exceeds $E_{k}$, the effective ionization time may be longer than the local Maxwell relaxation time. This can be clearly seen in the example where $E=2 E_{k}$ in Fig. $2 \mathrm{~b}$.

Therefore the comparison with the conventional breakdown field $E_{k}$ is not the only relevant factor that determines the effect of the external field on the atmosphere. Rather, we must consider the three timescales involved in the process: the timescale $\tau_{E}$, on which the external field rises, determined by the discharge process in the cloud; the Maxwell relaxation time $\tau_{M}$, determined by the local conductivity; and the effective ionization time $\tau_{i}=1 / v_{i, e f f}=1$ / $\left(v_{i}-v_{a}\right)$, where $v_{i}$ and $v_{a}$ are respectively the ionization and attachment rates. The ionization time depends on the local electric field and we define it only for $v_{i}>v_{a}$, i.e. for $E>E_{k}$. It is important to note that $\tau_{M}$ and $\tau_{i}$ depend dynamically on the local state of the atmosphere, including the electric field.

The first condition that must be satisfied for an appreciable impact of an applied electric field is that the electric field is not screened rapidly as it rises:

$\tau_{E} \lesssim \tau_{M}$,

with $\tau_{M}$ calculated from the initial conductivity. The electric field has two components which rise on different time scales: for the induction field $\tau_{E}=\tau_{2}$, the current rise time in Eq. (1) and for the QES field $\tau_{E}=\tau_{1}$, the current decay time. If this condition does not hold, the electric field will be screened from the conducting region while it rises externally, so that it cannot penetrate into the conducting region. The induction field rises faster than the QES field, and therefore can penetrate to higher altitudes. But even if Eq. (4) is satisfied, the field acts long enough to cause a significant increase of the electron density only if

$\tau_{M}>\tau_{i}$

a condition that we find useful to express in terms of a critical electric field $E_{c}$ defined by the relation

$v_{i, e f f}\left(E_{c} / N\right)=v_{i}\left(E_{c} / N\right)-v_{a}\left(E_{c} / N\right)=\frac{e \mu_{e} N_{e}}{\epsilon_{0}}$,

so that Eq. (5) reads $E>E_{c}$. We may check for this condition at any time but it is particularly relevant to investigate it when $E$ is the bare (unscreened) external field and $E_{c}$ reflects the initial electron density.

If the electric field is stationary after the fast initial rise, the Maxwell relaxation time can be generalized to the ionization screening time introduced by Sun et al. (2013) $\tau_{i s}=\tau_{i} \log \left(1+\tau_{M} /\right.$ $\tau_{i}$ ). This definition takes the change of electron density and conductivity during the electric screening process into account; in general it is smaller than the Maxwell time $\tau_{M}$ and it reduces to $\tau_{M}$ if $\tau_{M}<\tau_{i}$, and $\Delta N_{e}=N_{e}(t)-N_{e}(0) \ll N_{e}(0)$.

Note that Eq. (5) is a necessary condition for a significant relative increase in the electron density but it is not directly related to the absolute increase in ionization. In Appendix $C$ we show that the absolute increase in ionization caused by an electric field imposed instantaneously (i.e. $\tau_{E} \ll \tau_{M}$ ) and then kept constant is independent of the initial electron density and hence of $E_{c}$ (see also Li et al., 2007). In this paper we are interested in conditions of low initial electron density where only a large relative increase in ionization causes the kind of impact that we are looking for, so Eq. (5) still provides a useful criterion. Besides, a large relative increase in ionization represents a strong deviation from chemical equilibrium 
and, if it persists long enough, it may be detected by radio occultation techniques.

The rates in Eq. (6) and the electron mobility are found using the BOLSIG+ routine by Hagelaar and Pitchford (2005), using cross-sections from the Phelps compilation: $\mathrm{H}_{2}-$ Buckman and Phelps (1985), Crompton et al. (1969); He - Crompton et al. (1967, 1970), Milloy and Crompton (1977), Hayashi (1981). The $\mathrm{H}_{2}$ attachment crosssection was taken from Yoon et al. (2008). The rate coefficients, $k_{X}$, are plotted in Fig. 3; they are independent of neutral density. The ionization and attachment rate coefficients are plotted on the left of Fig. 3. The total effective ionization rate at a given altitude is $v_{i, e f f}=\left[\mathrm{H}_{2}\right] k_{i, \mathrm{H} 2}+[\mathrm{He}] k_{\mathrm{He}}-\left[\mathrm{H}_{2}\right] k_{a \mathrm{H} 2}$, where $k_{X}$ is the ionization coefficient in $\mathrm{H}_{2}$, He, and the attachment coefficient in $\mathrm{H}_{2} ;[X]$ is the density of the neutral species involved in the interaction. The conventional breakdown field $E_{k}$ is found where $v_{i, \text { eff }}$ equals 0 ; here it equals $46 \mathrm{Td}$. In the right panel of Fig. 3 we plot the excitation rates to the states $\mathrm{H}_{2}\left(\mathrm{a}^{3} \Sigma_{\mathrm{g}}^{+}\right)\left(\mathrm{UV}\right.$-continuum) and $\mathrm{H}_{2}\left(\mathrm{~d}^{3} \Pi_{\mathrm{u}}\right.$ ) (the Fulcher band).

The neutral density in Saturn's mesosphere is deduced from an interpolation of two measured data sets (Festou and Atreya (1982)), and described by an exponential function $N=N_{0} \exp (-h /$ $H$ ), where $N_{0}=3.5 \sim 10^{18} \mathrm{~cm}^{-3}$ and the scale height is $H=65 \mathrm{~km}$.

In Fig. 4 we show the reduced critical fields $E_{c} / N$ for the two $N_{e}$ profiles discussed in Section 3, and the reduced conventional electric breakdown field $E_{k} / N$. The conventional breakdown field is proportional to the neutral density, and is represented by a vertical line at $46 \mathrm{Td}$. The left hand side of Eq. (6) is negative if $E<E_{k}$, and therefore $E_{c}$ is not defined at all altitudes. We identify the lowest altitude where $E_{c}$ can be defined with the concept of a transition altitude as was proposed by Pasko et al. (1998). At this altitude the ionization, attachment and Maxwell times are of the same order of magnitude. Pasko and Stenbaek-Nielsen (2002) demonstrated how observed sprites can be used to estimate this altitude, and deduce the electron density there. Above the transition altitude streamers cannot develop, but halos can if the electric field is of the order of $E_{c}$ or higher. Below the transition altitude streamers may develop if the induced electric field is larger than $E_{k}$.

With profile (a) the transition altitude is approximately at $800 \mathrm{~km}$, and with profile (b) it is at $500 \mathrm{~km}$. If the external electric field exceeds $E_{k}$ below the transition altitude, streamers have a chance to form there. Above the transition altitude the impact on the electron density and chemical composition would be appreciable if $E>E_{c}$.

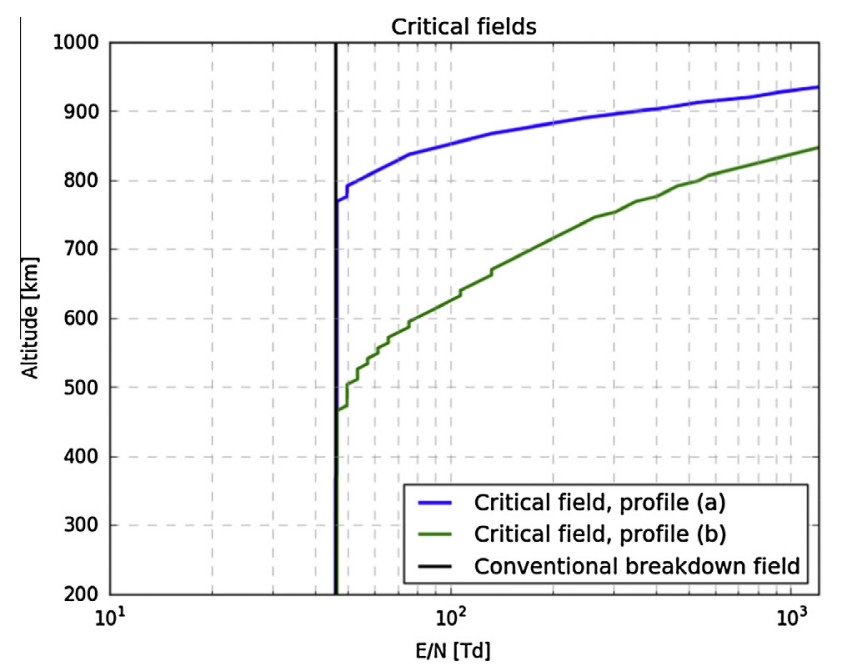

Fig. 4. Reduced breakdown and critical fields $\left(E_{k}\right.$ and $\left.E_{c}\right)$. The breakdown field scales with neutral density $N$, therefore in reduced units it appears as a vertical line at $46 \mathrm{Td}$. The reduced critical field is calculated using Eq. (6).

\section{Modeling electric fields in the upper atmosphere}

We model Saturn's atmospheric composition with 90\% Hydrogen and $10 \%$ Helium. The homopause is located roughly at $1000 \mathrm{~km}$ above the 1 bar level, Nagy et al. (2009). The dominant interaction on the time scale of the lightning discharge and the simulation time (a few milliseconds) is the electron impact ionization, while the electron loss processes are slow, as discussed in the previous section (see Fig. 3). We estimate the amount of photons emitted by a hypothetical TLE by calculating the density of excited hydrogen molecules: the transition $\mathrm{H}_{2}\left(d^{3} \Pi_{u}\right) \rightarrow \mathrm{H}_{2}\left(a^{3} \Sigma_{g}^{+}\right)$emits the Fulcher bands, and $\mathrm{H}_{2}\left(\mathrm{a}^{3} \Sigma_{\mathrm{g}}^{+}\right) \rightarrow \mathrm{H}_{2}\left(\mathrm{~b}^{3} \Sigma_{\mathrm{u}}\right)$ emits a continuum in the near UV. Non-radiative de-excitation processes such as collisional quenching with $\mathrm{H}_{2}$ are negligible at the relevant altitudes (Thompson and Fowler, 1972; Bretagne et al., 1981). The excited molecules emit photons and relax to the ground state almost instantly; therefore the density of excited species can be used as the density of radiated photons (see Astashkevich and Lavrov (2002) for radiative life-times).

The electric field is computed by means of a self-consistent zerodimensional model formulated in Luque and Gordillo-Vázquez
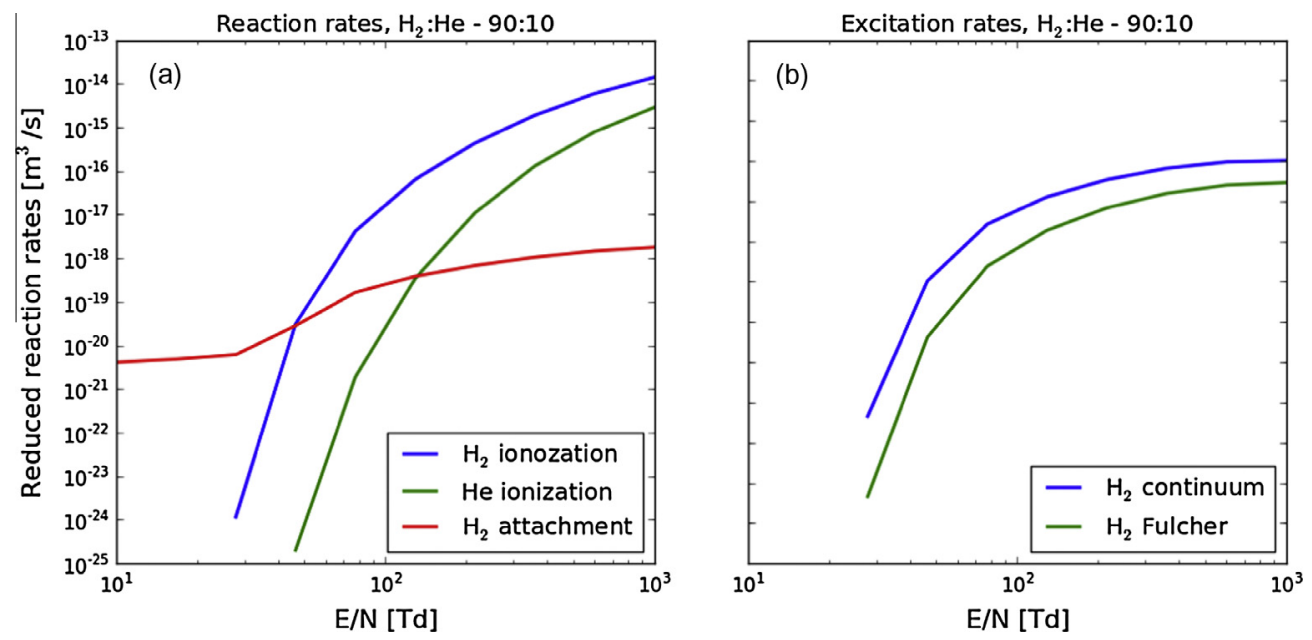

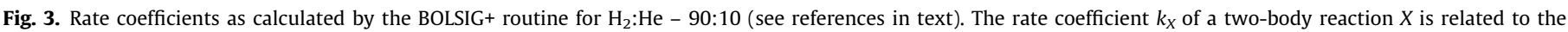

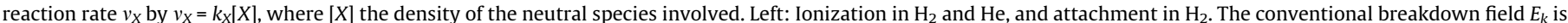

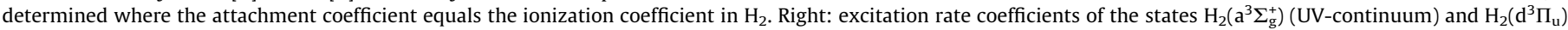
(the Fulcher band) 
(2011, supplementary information). Under the assumptions of planar symmetry and the conservation of total current,

$\partial_{t} E(t)=\partial_{t} E_{p}(t)-\left(\sigma / \epsilon_{0}\right) E(t)$,

where $E$ is the total electric field, $E_{p}$ is the field induced by the lightning flash, defined in Section 2.2, Eq. (2). Electron drift is neglected. The conductivity $\sigma(t)$ depends on the local electron density $N_{e}$, which is determined by the rate equation

$\partial_{t} N_{e}=v_{i} N_{e}$.

Eqs. (7) and (8) are computed for each altitude separately.

The ambient electron densities at $t=0$ (profiles (a) and (b)) are discussed in Section 3. The duration of the parent lightning is important, as it determines the maximum intensity of the induced electric field, before it is screened by the local conductivity. In this work we use $\tau_{2}=0.1 \mathrm{~ms}$ and $\tau_{1}=1 \mathrm{~ms}$, as discussed in Section 2 . We test three values for the total charge moment change: $M=10^{4}, 10^{5}$ and $10^{6} \mathrm{C} \mathrm{km}$ located at $-110 \mathrm{~km}$. Later in the text we refer to this model as the $1 \mathrm{D}$ model.

The results are plotted in Figs. 5 and 6 for profile (a) and profile (b) respectively. The plots are organized as follows: each row shows the output for a different CMC: (a) for $M=10^{4} \mathrm{C} \mathrm{km}$, (b) for $M=10^{5} \mathrm{C} \mathrm{km}$, and (c) for $M=10^{6} \mathrm{C} \mathrm{km}$ (only in Fig. 6, profile (b). The color plots on the left show the reduced electric field $E / N$ as function of altitude (vertical axis) and the time elapsed after the start of the flash (horizontal axis). The electric field is retarded, as can be seen from the positive slope. The time step in these runs is $5 \mu \mathrm{s}$. The color scale is indicated to the right; scales are not identical. The plots on the right show the altitude profile of the electron density enhancement, $N_{e}(t)-N_{e}(0), 5 \mathrm{~ms}$ after the beginning of the flash, and the cumulative densities of $\mathrm{H}_{2}$ molecules emitting in the UV continuum and the Fulcher band at this time. Below we describe the results.
With profile (a) we used two CMC values, $10^{4}$ and $10^{5} \mathrm{C} \mathrm{km}$ (Fig. 5). With $M=10^{4} \mathrm{C} \mathrm{km}$ the electric field is higher than the critical field $E_{c}$ ( $E_{c}$ is $100 \mathrm{Td}$ at $850 \mathrm{~km}$ ) above the transition altitude (at $\sim 800 \mathrm{~km}$ ). Photon and electron production at $900 \mathrm{~km}$ is less than $0.1 \mathrm{~cm}^{-3}$, approximately $50 \%$ of initial electron density. Just below the transition altitude the electric field is a higher than $E_{k}$, reaching $60 \mathrm{Td}$ at $780 \mathrm{~km}$. With $M=10^{5} \mathrm{C} \mathrm{km}$ considerable fields are obtained between 700 and $900 \mathrm{~km}$, up to $1100 \mathrm{Td}$, stronger that the critical field $E_{c}$ at the corresponding altitudes. The electron density is increased considerably; UV photon and electron production peak at $750 \mathrm{~km}$ with density $\sim 30$ and respectively $50 \mathrm{~cm}^{-3}$. Below the transition altitude the electric field exceeds $E_{k}$. It is important to note here that the reaction rates are calculated in BOLSIG+ for electric fields smaller than $1200 \mathrm{Td}$. Above this field electrons approach relativistic energies, and the classical approach can no longer be applied. For this reason we do not test $M=10^{6} \mathrm{C} \mathrm{km}$ with profile (a).

With Profile (b) we tried three CMC configurations, $10^{4}, 10^{5}$ and $10^{6} \mathrm{C} \mathrm{km}$ (Fig. 6). With $M=10^{4} \mathrm{C} \mathrm{km}$ the electric field is very low, there is no change in electron density, and no photon emission. With $M=10^{5} \mathrm{C} \mathrm{km}$ the electric field does not exceed $E_{c}$ above the transition altitude $(\sim 500 \mathrm{~km})$ and the electron production is around $1 \%$ of the initial density. UV photon emission peaks at $700 \mathrm{~km}$ with $6 \mathrm{~cm}^{-3}$. The electron density increases by less than $1 \mathrm{~cm}^{-3}$ at this altitude. Below the transition altitude $E$ is lower than $E_{k}$, therefore streamers cannot form. In the extreme scenario $M=10^{6} \mathrm{C} \mathrm{km}$, the electric field reaches high values at a very short time, and decays fast, but a smaller time step leads to identical results. There is considerable electron and photon production in the entire range. Photon emissions peak at $500 \mathrm{~km}$ with $10^{4} \mathrm{~cm}^{-3}$ and electron production at this altitude is near $3 \times 10^{3} \mathrm{~cm}^{-3}$. Below the transition altitude electric field exceeds $E_{k}$.
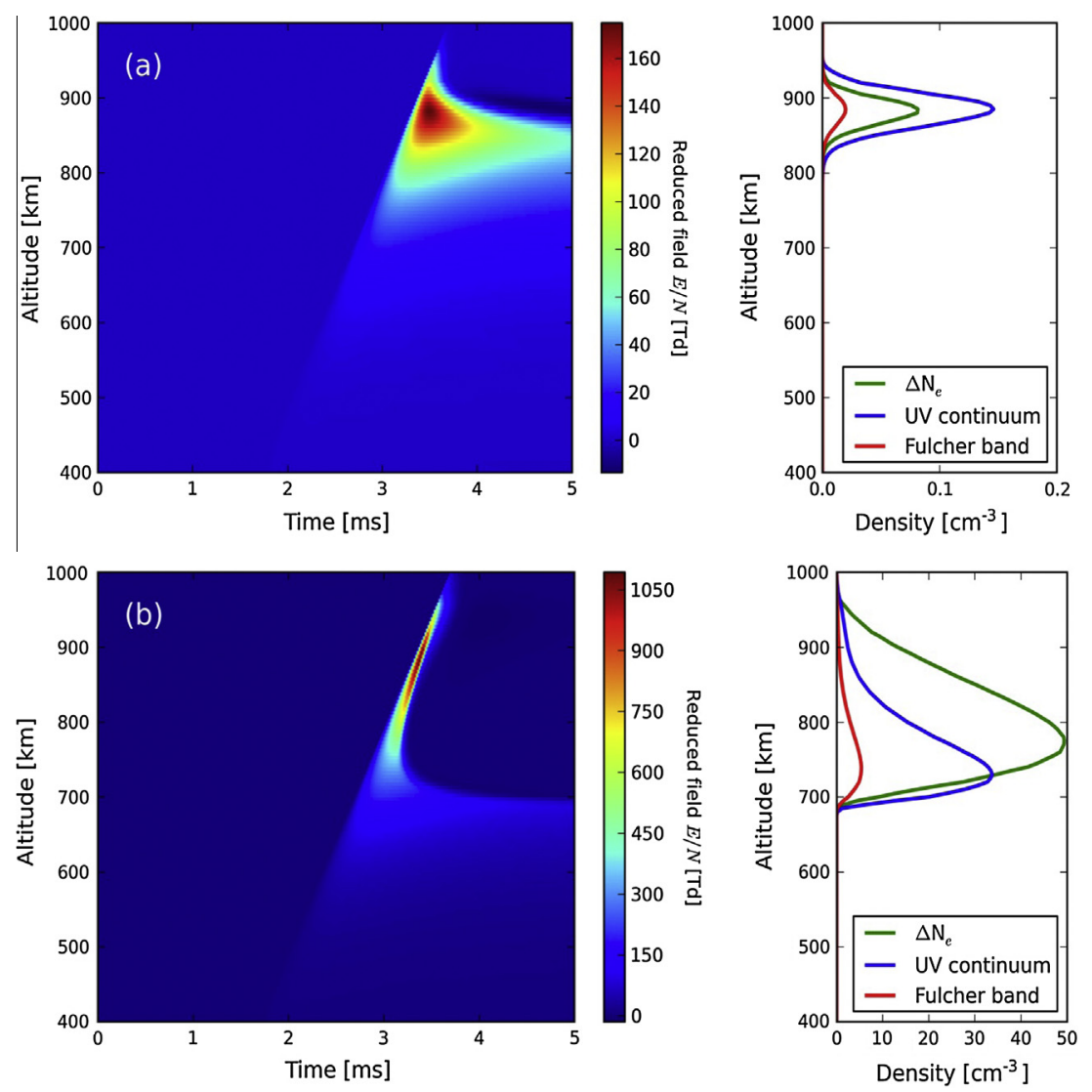

Fig. 5. Output for profile (a) - top row (a): $M=10^{4} \mathrm{C} \mathrm{km}$, bottom row (b): $M=10^{5} \mathrm{C} \mathrm{km}$. See details in text. 

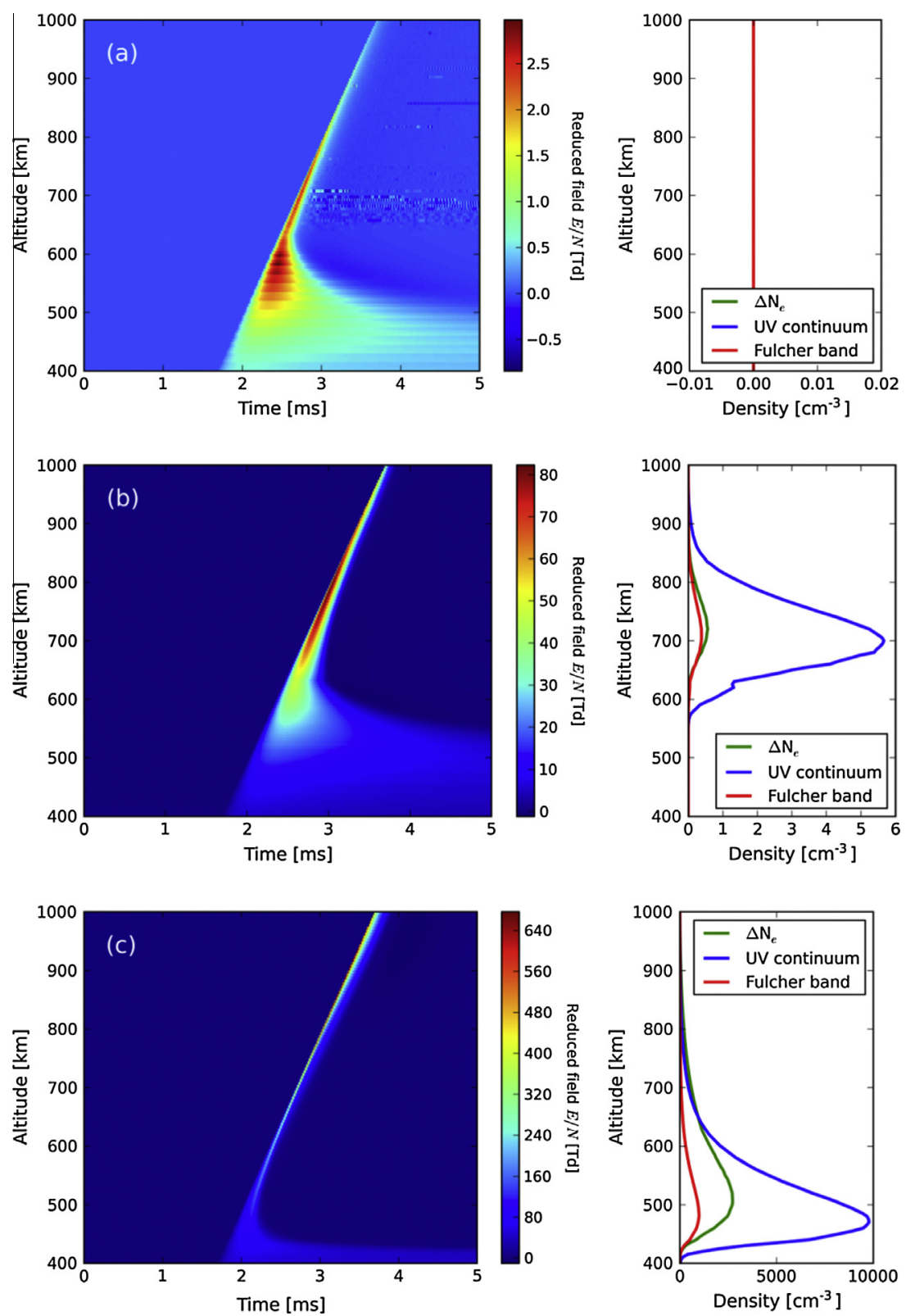

Fig. 6. Output for profile (b) - top row (a): $M=10^{4} \mathrm{C} \mathrm{km;} \mathrm{middle} \mathrm{row} \mathrm{(b):} M=10^{5} \mathrm{C} \mathrm{km}$; bottom row (c): $M=10^{6} \mathrm{C}$ km. See details in text.

The number of photons emitted by the event can be estimated, by multiplying the emission volume by the density of emitting species. The vertical and horizontal extents of all events are of the order of $100 \mathrm{~km}$. Therefore with $M=10^{5} \mathrm{C} \mathrm{km}$ and conductivity profile (a) the total number of photons is $\sim\left(30 \mathrm{~cm}^{-3}\right) \times(100 \mathrm{~km})^{2}$ $\times(100 \mathrm{~km}) \sim 3 \times 10^{22} \mathrm{UV}$ continuum photons. With profile (b) and $M=10^{5} \mathrm{C} \mathrm{km}$ it is one order of magnitude less, $\sim 6 \times 10^{21}$ photons, and in the extreme scenario $M=10^{6} \mathrm{C} \mathrm{km}, \sim 10^{25}$ photons can be emitted. The ISS camera on board Cassini is capable of detecting lightning with a total optical energy of $10^{8} \mathrm{~J}$ (Dyudina et al., 2010). These events where observed with the broad band filter, centered at $650 \mathrm{~nm}$. Assuming all the photons have the same wavelength, this implies that an event which emits less than $10^{26}$ photons would not be detected.

When conventional breakdown field is exceeded below the transition altitude (Pasko et al., 1998), than streamers can form if the field persists for a long enough time. We find that with profile (a) this condition is met with both CMC values; with profile (b) the conventional breakdown field is exceeded below the transition altitude only for the extreme case of $10^{6} \mathrm{C} \mathrm{km}$. If streamers indeed form in these scenarios, a sprite can develop, which could be significantly brighter than the halo.

\section{The chemical impact of TLEs}

The investigations about the possible existence of TLEs (sprites, halos and/or elves) in the upper atmosphere of Saturn requires the understanding of not only the plausible physical mechanisms underlying their generation but also should cover a rigorous analysis of the possible chemical influence of such upper atmospheric discharges in the mesosphere and lower ionosphere of Saturn. For doing that, we have developed a kinetic model in order to explore the chemical impact of transient $\mathrm{H}_{2}(90 \%) / \mathrm{He}(10 \%)$ plasmas generated by possible saturnian TLEs.

The basic model equations controlling the non-equilibrium $\mathrm{H}_{2} /$ He plasma chemistry are a set of self-consistently solved time- 
dependent equations formed by the continuity equations for each of the species considered (ground neutrals, excited neutrals as well as positive and negative ions and electrons); the time-dependent, spatially-uniform Boltzmann equation controlling the energy distribution function of the free $\mathrm{H}_{2} / \mathrm{He}$ plasma electrons; and Eq. (7) in Section 5 to derive self-consistently the lightning-generated electric field. The present saturnian TLE kinetic model is based on previous models that we have developed for the kinetics of TLEs on Earth (Gordillo-Vázquez, 2008, 2010; Parra-Rojas et al., 2013).

The Saturn kinetic model requires a set of electric and kinetic inputs. The electric inputs are the values $\left(10^{5} \mathrm{C} \mathrm{km}\right.$ and $10^{6} \mathrm{C} \mathrm{km}$ ) considered for the charge moment changes (CMC) and the bi-exponential function shown in Eq. (1) in Section 2 for the electric current flowing through the lightning channel, assuming a stroke duration ( $\tau_{1}=1 \mathrm{~ms}$ ) ten times longer than the current rise time $\left(\tau_{2}=0.1 \mathrm{~ms}\right)$. The kinetic inputs are basically the cross sections and rate coefficients needed for the different kinetic reactions considered in the calculations.

The chemical species considered in this $\mathrm{H}_{2} / \mathrm{He}$ global model for the plasma kinetics of possible Saturn TLEs are listed in Appendix A. We have taken into consideration a total of 32 species classified into ground neutrals (3), electronically and vibrationally excited neutrals (21), electrons and negative ions (2) and positive ions (6). The exact number of reactions considered is 160 , where there are electron-driven reactions (77), neutral-neutral reactions (41) including 11 Penning ionization mechanisms, ion-ion recombination mechanisms (9), ion-neutral processes (18, with 16 positive ion-neutral reactions and 2 negative ion-neutral reactions) and radiative spontaneous de-excitation channels (15). The complete list of all the reactions considered and their corresponding rate coefficients are shown in Appendix B. There are 48 electron-impact reactions indicated as electron energy distribution function (EEDF)-dependent processes for which their rate coefficients are not shown explicitly because they are self-consistently calculated using available cross sections. The reference of each of the crosssections and/or rates used for all the considered reactions is indicated in the last column of each of the tables in Appendix B. At the present stage the model does not include photochemistry (night-time conditions are assumed) nor diffusion.

In modeling the kinetics of hydrogen plasmas we have also considered electron impact dissociative attachment of $\mathrm{H}_{2}$. Although the cross section for dissociative attachment of $\mathrm{H}_{2}$ is quite small for the lowest vibrational level of the ground electronic state $\left(\mathrm{H}_{2}\left(\mathrm{X}^{1} \Sigma_{\mathrm{g}}^{+}, v=0\right)\right)$, they increase rapidly with increasing vibrational levels (Bardsley and Wadehra, 1979). Since the attachment cross sections show a peak $\left(\sigma_{\text {peak }}(v)\right)$ at the threshold energies $\left(\varepsilon_{t h}(v)\right)$ and a fast reduction in magnitude as the energy is increased above the threshold, Celiberto et al. (2001) proposed to fit the attachment cross section of $\mathrm{H}_{2}\left(\mathrm{X}^{1} \Sigma_{\mathrm{g}}^{+}, v\right)$ just above the threshold by the convenient analytic expression $\sigma_{D A}(\varepsilon)=\sigma_{\text {peak }}(v) \exp \left(-\left(\varepsilon-\varepsilon_{t h}(v)\right) / \varepsilon_{g}\right) \quad$ with $\varepsilon_{g}=0.45 \mathrm{eV}$. We considered dissociative attachment cross sections of $\mathrm{H}_{2}\left(\mathrm{X}^{1} \Sigma_{\mathrm{g}}^{+}, v\right)$ up to $v=9$ using the values of $\sigma_{\text {peak }}(v)$ and $\varepsilon_{t h}(v)$ given by Bardsley and Wadehra (1979).

The kinetic model covers the altitude range between $450 \mathrm{~km}$ and $1000 \mathrm{~km}$ above Saturn's 1 bar level. We considered electron and neutral density as discussed above, and used the same settings (except $M=10^{4} \mathrm{C} \mathrm{km}$ ) as in Figs. 5 and 6 . The gas temperature $\left(T_{g}\right)$ is considered to be constant and equal to $125 \mathrm{~K} \mathrm{Nagy}$ et al. (2009) for the altitudes investigated with this model, and we assumed that possible TLEs in Saturn occur below the thermosphere. Finally,
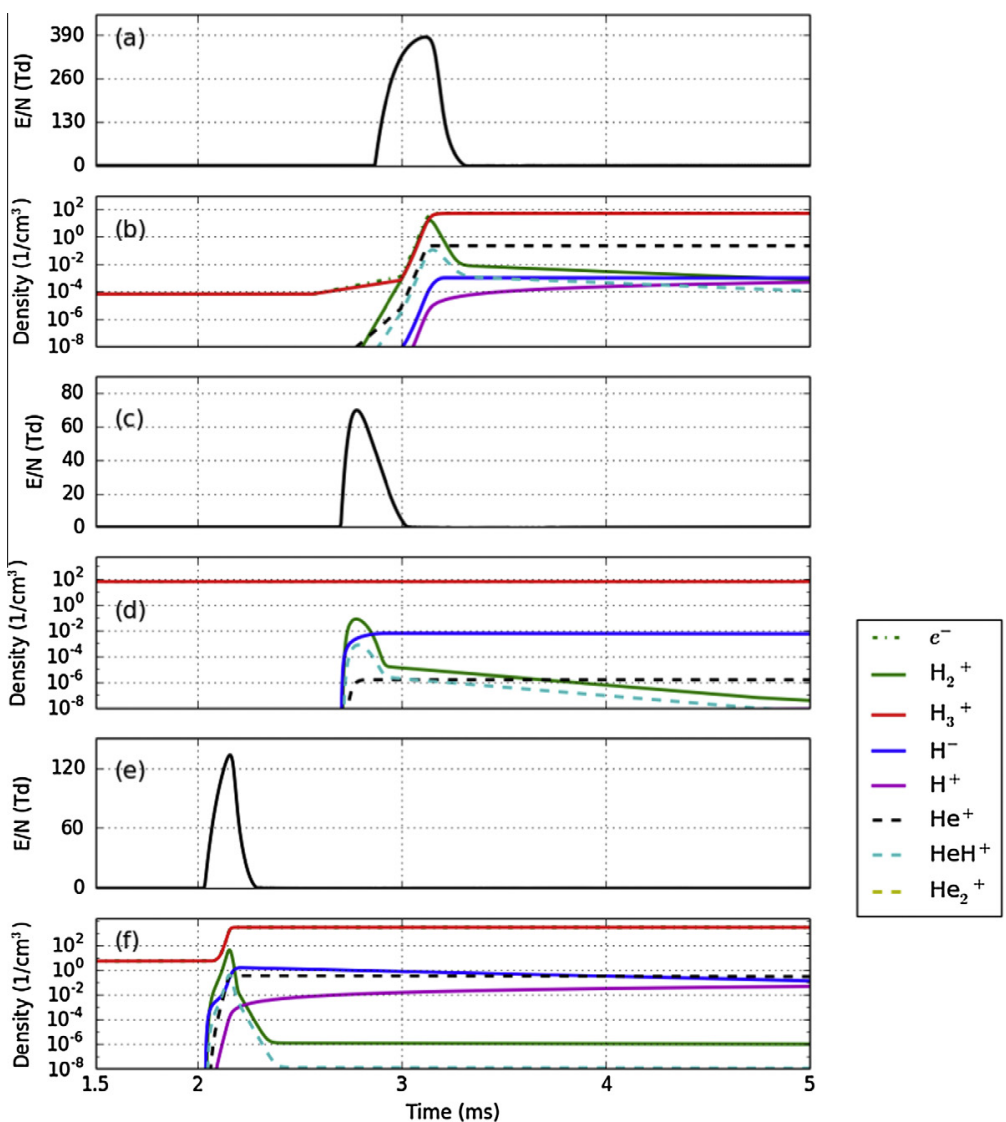

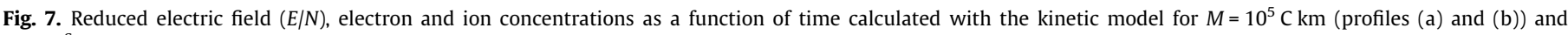

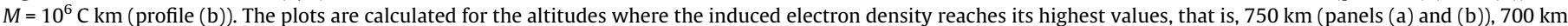

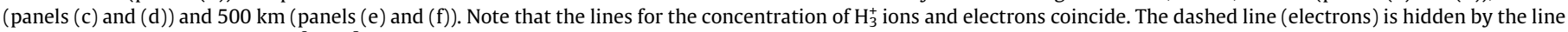
of $\mathrm{H}_{3}^{+}$. Concentrations below $10^{-8} \mathrm{~cm}^{-3}$ are not plotted. 
the plasma is assumed to be optically thin $(\kappa=1)$ and the plasma kinetics is simulated during $5 \mathrm{~ms}$.

The results for the electron density and the different ion concentrations obtained from the kinetic model are shown in Fig. 7 for the altitudes in which, for each of the cases considered, the electron density reaches its highest value. In plotting Fig. 7, we have considered the $M=10^{5} \mathrm{C} \mathrm{km}$ and $10^{6} \mathrm{C} \mathrm{km}$ cases shown in Figs. 5 and 6. Panels (b) and (d) of Fig. 7 show the ion concentrations for $M=10^{5} \mathrm{C} \mathrm{km}$ at $750 \mathrm{~km}$ and $700 \mathrm{~km}$ with, respectively, electron density profiles (a) and (b), and in the lower panel (f) we have used $M=10^{6} \mathrm{C} \mathrm{km}$ at $500 \mathrm{~km}$ with the electron density profile (b). The initial concentrations of all ions are zero except for $\mathrm{H}_{2}^{+}$which, at $t=0 \mathrm{~s}$, is assumed the same as the initial electron density considered. Note that panels (a), (c) and (e) of Fig. 7 represent the reduced electric field $(E / N)$ versus time for, respectively, the altitudes $750 \mathrm{~km}, 700 \mathrm{~km}$ and $500 \mathrm{~km}$, with corresponding ion kinetics shown in panels (b), (d) and (f).

The first feature we notice in the three cases shown in Fig. 7 is that the electron density enhancement $\left(N_{e}(t)-N_{e}(0)\right)$ at $t=5 \mathrm{~ms}$ is the same as the one obtained with the 1D dynamic model described in Section 5. Moreover, it is interesting to note that while the dominant source of electrons is electron impact ionization of $\mathrm{H}_{2}$ producing $\mathrm{H}_{2}^{+}$, we note that $\mathrm{H}_{2}^{+}$ions are quickly (between one and several tens of microseconds) converted to $\mathrm{H}_{3}^{+}$ions through the fast reaction $\mathrm{H}_{2}^{+}+\mathrm{H}_{2} \rightarrow \mathrm{H}_{3}^{+}+\mathrm{H}$ so that $\mathrm{H}_{3}^{+}$becomes the dominant ion. It can be seen in Fig. 7 that the higher the altitude, the longer the time the lightning originated electromagnetic pulse takes to travel from the thundercloud layer (see panels (a), (c) and (e)). Consequently, the kinetic influence triggered by the arriving electric field initiates with a slight delay at $750 \mathrm{~km}$ (upper panel) than at $500 \mathrm{~km}$ (lower panel). When CMC remains the same $\left(10^{5} \mathrm{C} \mathrm{km}\right)$ and profiles (a) and (b) are compared (shown in panels (b) and (d) of Fig. 7) the concentration of the positive ion $\mathrm{He}^{+}$after $t=3 \mathrm{~ms}$ is the highest one after that of $\mathrm{H}_{3}^{+}$with profile (a) while it is negligible with profile (b). However, when profile (b) is used as the initial electron density profile and the $\mathrm{CMC}$ increases from $10^{5} \mathrm{C} \mathrm{km}$ at $700 \mathrm{~km}$ to $10^{6} \mathrm{C} \mathrm{km}$ at $500 \mathrm{~km}$ (panels (d) and (f) in Fig. 7) the reduced electric field $(E / N)$ increases from about $65 \mathrm{Td}$ to $125 \mathrm{Td}$ (see panels (c) and (e) of Fig. 7). The latter significant increase of the field when $M=10^{6} \mathrm{C} \mathrm{km}$ produces a sharp growth of more than two orders of magnitude in the ambient electron density up to nearly $3500 \mathrm{~cm}^{-3}$ (see lower panel in Fig. 7). During the field duration, direct electron impact ionization drives the production of electrons. However, once the field is off after $3.20 \mathrm{~ms}$ (upper panel in Fig. 7), $3.00 \mathrm{~ms}$ (panel (c) in Fig. 7) and $2.25 \mathrm{~ms}$ (panel (e) in Fig. 7), the production of electrons is dominated by Penning ionization, $\mathrm{He}\left(2 \mathrm{~s}^{2}{ }^{3} \mathrm{~S}\right)+\mathrm{H}_{2} \rightarrow \mathrm{H}_{2}^{+}+\mathrm{He}+\mathrm{e}$ and $\mathrm{He}\left(2 \mathrm{~s}^{2}{ }^{3} \mathrm{~S}\right)+\mathrm{H}_{2} \rightarrow \mathrm{H}+\mathrm{HeH}^{+}+\mathrm{e}$, when $\mathrm{M}=10^{5} \mathrm{C} \mathrm{km}$ with profile (a) is used, and by electron detachment, $\mathrm{H}^{-}+\mathrm{He} \rightarrow \mathrm{H}+\mathrm{He}+\mathrm{e}$, when $M=10^{5} \mathrm{C} \mathrm{km}$ and $M=10^{6} \mathrm{C} \mathrm{km}$ with profile (b) are used.

The increase of the concentration of $\mathrm{H}^{+}$right after the end of the electric field pulse in panels (b) and (f) is due to $\mathrm{He}^{+}+\mathrm{H}_{2} \rightarrow \mathrm{H}^{+}+\mathrm{H}+\mathrm{He}$. However, the behavior of $\mathrm{H}^{-}$after the end of the electric field pulse changes when different CMCs and initial electron density profiles are used. In this regard, $\mathrm{H}^{-}$remains constant or decreases when $M=10^{5} \mathrm{C} \mathrm{km}$ and profile (a), or $M=10^{6} \mathrm{C} \mathrm{km}$ and profile (b) are used. This is connected to the electron detachment loss rate of the $\mathrm{H}^{-}$previously produced by electron attachment $\left(e+\mathrm{H}_{2} \rightarrow \mathrm{H}^{-}+\mathrm{H}\right)$ when the field is on: a small or a high loss rate with respect to the $\mathrm{H}^{-}$field-dependent attachment production rate keeps $\mathrm{H}^{-}$constant (see panels (b) and (d)) or makes $\mathrm{H}^{-}$decrease (lower panel), respectively.

The concentrations of the helium ions considered $\left(\mathrm{He}^{+}, \mathrm{He}_{2}^{+}\right.$and $\mathrm{HeH}^{+}$) are usually very small except for $\mathrm{He}^{+}$when $M=10^{5} \mathrm{C} \mathrm{km}$ and profile (a) (panel (b) of Fig. 7) and $M=10^{6} \mathrm{C} \mathrm{km}$ and profile (b) (lower panel of Fig. 7) are used; in those cases, $\mathrm{He}^{+}$becomes the second most important positive ion after $\mathrm{H}_{3}^{+}$for $t>3 \mathrm{~ms}$ and $4 \mathrm{~ms}$, respectively.

We show in Figs. 8 and 9, the altitude-dependent instantaneous and cumulative number of $\mathrm{H}_{2}$ continuum (UV) and Fulcher photons calculated with the full kinetic model presented in this paper. The panels in the left and right hand sides of Figs. 8 and 9 correspond respectively to the UV and Fulcher emissions associated to the same $\mathrm{CMC}$ and ambient electron density profiles discussed in Fig. 7. In general, both UV and Fulcher emissions are very fast with UV emissions being slightly stronger than the Fulcher ones. In Fig. 8, where the instantaneous emissions are represented, it is interesting to note that both types of optical emissions are a bit longer for lower
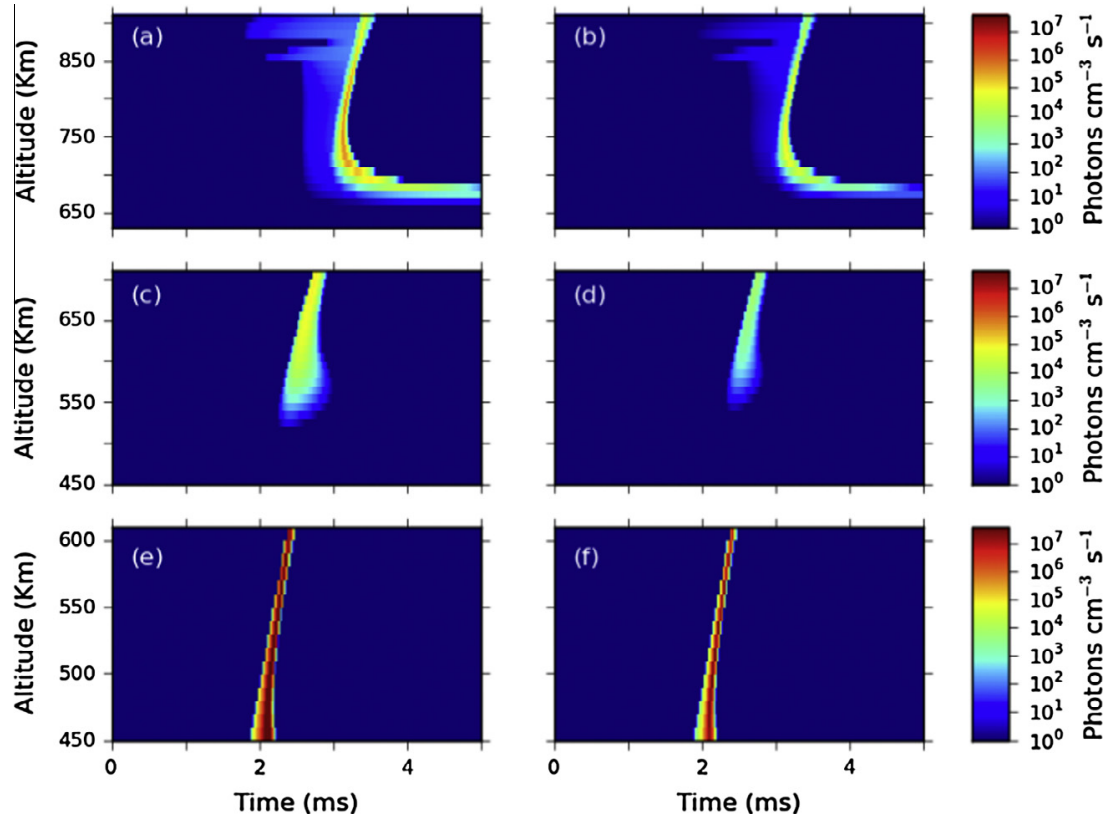

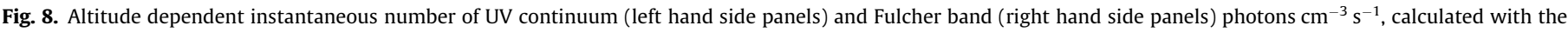
kinetic model for the same CMC and ambient electron density profiles as in Fig. 7. 
altitudes. The latter effect (longer optical emissions at lower altitudes) is related to the slower relaxation times at these altitudes. On the other hand, the cumulative number of UV photons calculated with the kinetic model (see Fig. 9) gives the same values as those obtained with the 1D dynamic model, except for the number of UV photons calculated with $M=10^{5} \mathrm{C} \mathrm{km}$ using profile (b) where a difference of less than factor two is found. If the base of the ionosphere is at $1000 \mathrm{~km}$ (profile (a)) above the 1 bar level, the kinetic model predicts 40 and $6 \mathrm{UV}$ and Fulcher photons $\mathrm{cm}^{-3}$, respectively, at $700 \mathrm{~km}$ with $M=10^{5} \mathrm{C} \mathrm{km}$. However, if the base of the ionosphere is at $600 \mathrm{~km}$ (profile (b)), the kinetic model predicts $\sim 9$ and $\sim 0.6$ UV and Fulcher photons $\mathrm{cm}^{-3}$, respectively, at $680 \mathrm{~km}$ with $M=10^{5} \mathrm{C} \mathrm{km}$, and $\sim 10,000$ and $\sim 1000 \mathrm{UV}$ and Fulcher photons $\mathrm{cm}^{-3}$, respectively, at $475 \mathrm{~km}$ with $M=10^{6} \mathrm{C} \mathrm{km}$.

We have also calculated (not shown) the concentration of $\mathrm{H}(n=3)$ and the corresponding cumulative number of Balmer photons $\mathrm{cm}^{-3}(656.28 \mathrm{~nm})$, which is two orders of magnitude lower than the number of continuum $\mathrm{H}_{2}$ UV photons.

\section{Discussion and conclusions}

In this work we examine the impact of lightning in Saturn's atmosphere on the planet's lower ionosphere. We review the known constraints on the energies and locations of lightning flashes and the conductivity and electron density profiles of Saturn's atmosphere in Sections 2 and 3. Within these constraints, we suggest that charge moment change of these lightning flashes can range from $10^{4}$ to $10^{5} \mathrm{C} \mathrm{km}$, with $10^{6} \mathrm{C} \mathrm{km}$ as an extreme scenario. We assume that the lightning flash depth is at $-110 \mathrm{~km}$ below the 1 bar pressure level, a region where deep convective $\mathrm{H}_{2} \mathrm{O}$ clouds reside. According to models, it appears that the electron density is strongly decreased below $1000 \mathrm{~km}$ above the 1 bar level, however this effect is yet to be measured. We use existing models to simulate two possible electron density profiles; one places the bottom of the ionosphere around $1000 \mathrm{~km}$, and the other at $600 \mathrm{~km}$ above the 1 bar level.
In the conventional breakdown approach, electrical breakdown in the gas occurs when the induced electric field exceeds $E_{k}$. In Section 4 we show that in Saturn's mesosphere an electric field higher than $E_{k}$ may not cause a significant increase of the local electron density, if the electric field screening is faster than ionization. We express this condition in terms of a critical electric field $E_{c}$, based on the competition between two time scales - the initial Maxwell relaxation time and the typical ionization time. If the induced electric field exceeds $E_{c}$, then the electron density can grow by several orders of magnitude, but if it is smaller than $E_{c}$ then the relative growth of the local electron density is small. Photons are produced also when $E<E_{c}$; if the initial electron density is high, then a considerable amount of photons could be emitted. This is an additional constraint on the formation of halos in the weakly conducting atmosphere, above the transition altitude (as defined by Pasko et al. (1998)). At transition altitude the Maxwell relaxation time is comparable with ionization and attachment times at $E=E_{k}$, and $E_{c} \sim E_{k}$, below this altitude $E_{c}$ is not defined; in other words the conductivity of the atmosphere can be neglected. Above the transition altitude Maxwell screening of the electric field limits the ionization reactions as well as the magnitude of the applied field. Below the transition altitude sprites may form if the electric field exceeds $E_{k}$.

The modeling of halos and sprites on Earth is generally based on the quasi-electrostatic heating model of the lower ionosphere (Pasko et al., 2012). It is generally assumed that the electric field is determined by the charge moment change of the flash, and sets in immediately at all altitudes. This assumption works well for the short distances on Earth, where $z<100 \mathrm{~km}$. The electric field reaches its maximum on the time scale of the flash duration ( $\tau_{2}$ in Eq. (1), see Fig. 1). At higher altitudes, where neutral density is lower, the reduced electric field exceeds breakdown conditions $\left(E_{k}\right.$ and $E_{c}$ ) earlier than at lower altitudes. The result is the formation of the well documented downward propagating halo.

On planets with larger atmospheric scale heights, such as Saturn, where the relevant length scales are on the order of several
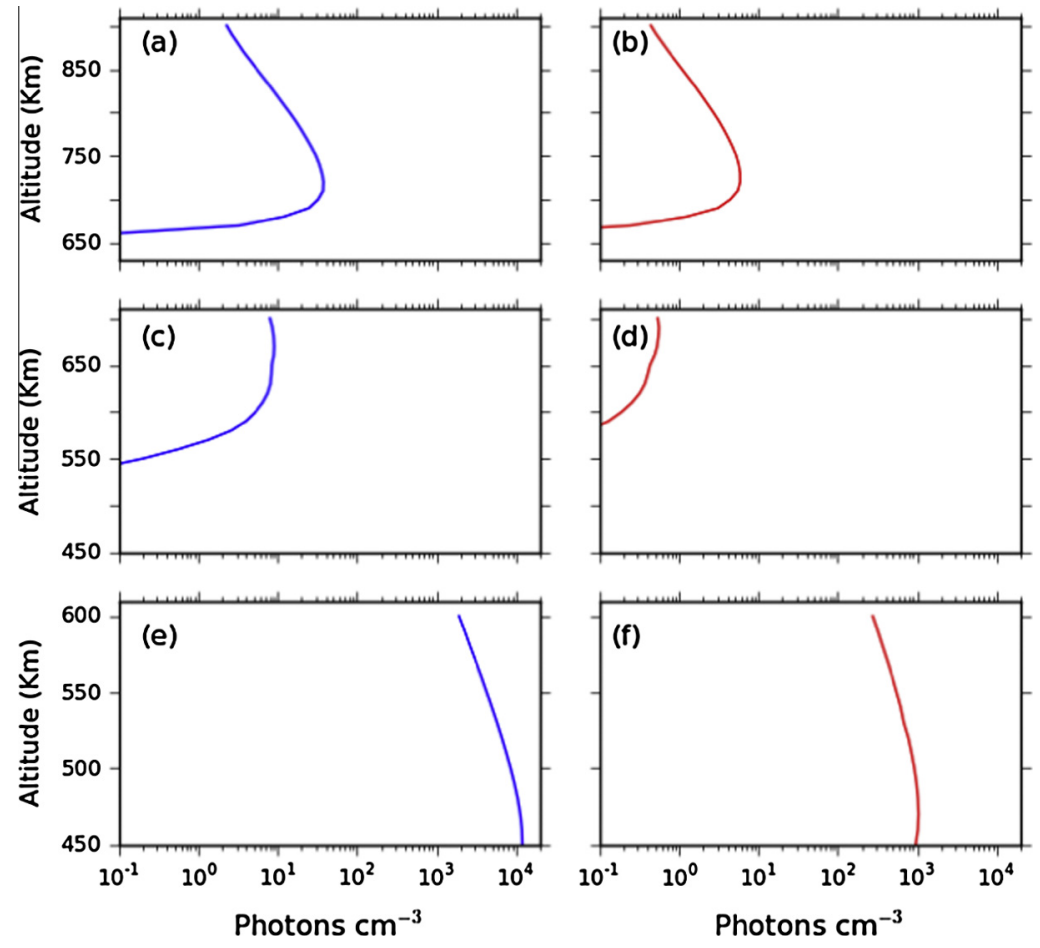

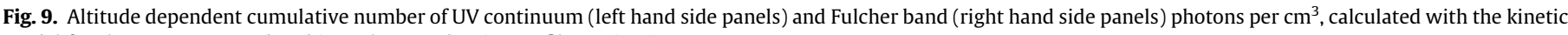
model for the same CMC and ambient electron density profiles as in Fig. 7. 
hundreds of kilometers, the propagation of the field in space cannot be neglected (in other words, it cannot be assumed to be immediate). Moreover, at a distance longer than $100 \mathrm{~km}$ the radiation and induction components of the retarded field are significantly stronger than the quasi electro-static (QES) component (see Section 2.2). Directly above the vertical lightning channel the dominant component is the induction field. In our analysis we find that a halo in Saturn's atmosphere would propagate upward.

In Section 5 we use a self-consistent one-dimensional model to calculate the effect of the electric field on the electron density, the photon production, and the altitude range of the event. We test several case studies based on the limited knowledge of Saturn's electron conductivity profile at the bottom side of the ionosphere, and the lightning flash characteristics. With profile (a), where the base of the ionosphere is around $1000 \mathrm{~km}$, we find that a very faint halo may be produced by $M=10^{4} \mathrm{C} \mathrm{km}$; with $M=10^{5} \mathrm{C} \mathrm{km}$ electron density grows by orders of magnitude, but since the initial electron density is very low the density of produced photons is $\sim 30 \mathrm{~cm}^{-3}$ in the altitude range of $700-800 \mathrm{~km}$ above the 1 bar level. In both scenarios $E$ exceeds $E_{k}$ below the transition altitude $(800 \mathrm{~km})$, suggesting that streamers may form there. However, this needs to be tested further with a more detailed model.

With profile (b) where the base of the ionosphere is around $600 \mathrm{~km}$, we find that a charge moment change $M=10^{4} \mathrm{C} \mathrm{km}$ is screened completely by the ionosphere. With $M=10^{5} \mathrm{C} \mathrm{km}$ the electric field exceeds $E_{k}$ above $\sim 600 \mathrm{~km}$ but does not exceed $E_{c}$. As a result the electron density increases by about $1 \%$. The initial electron density above $600 \mathrm{~km}$ is $\sim 10^{1} \mathrm{~cm}^{-3}$, as a result a faint halo is created with a peak photon production at $700 \mathrm{~km}$, $5 \mathrm{~cm}^{-3}$. With this profile we test also the extreme scenario of $M=10^{6} \mathrm{C} \mathrm{km}$. In this scenario the electric field increases considerably in the entire range; peak photon production is at $500 \mathrm{~km}$, with $10^{4} \mathrm{~cm}^{-3}$ UV photons. With profile (b) $E_{k}$ is exceeded below the transition altitude $(500 \mathrm{~km})$ only in the extreme case $M=10^{6} \mathrm{C} \mathrm{km}$.

We conclude that faint halos may form in both cases, and therefore for any intermediate electron density profile. The brightest halos would be created by $M=10^{5} \mathrm{C} \mathrm{km}$ with profile (a), with a total number of emitted photons of the order of $10^{22}$, and by $M=10^{6} \mathrm{C} \mathrm{km}$ with profile (b), with $\sim 10^{25}$ photons. Either of these events is below the current observation limit of the ISS camera on-board the Cassini spacecraft. On the other hand, sprites may form if the ionosphere is closer in nature to profile (a). On Earth sprites typically emit considerably more light than halos due to the local enhancement of the electric field (see e.g. Kuo et al., 2008; Luque and Ebert, 2009). If a sprite-like TLE is observed on Saturn, it would suggest that the carbo-hydrate photo-ionization layer is weaker than suggested in Galand et al. (2009). Based on geometric considerations we would expect the halo to extend at least a $100 \mathrm{~km}$ in radius in the lateral direction; a sprite would be much more concentrated.

In Section 6 we present a self-consistent kinetic model that was developed to analyze the atmospheric chemical disturbances caused by possible saturnian upper atmospheric electric discharges. We have used our kinetic model in the same conditions used in the 1D dynamic model and calculated the altitude and time-dependent behavior of the electron and ion densities together with the instantaneous and cumulative number of photons emitted by $\mathrm{H}_{2}$ UV continuum and Fulcher bands originated by a halolike event in Saturn's mesosphere. We found that $\mathrm{H}_{3}^{+}$ions are rapidly produced from the parent $\mathrm{H}_{2}^{+}$ions through the fast reaction $\mathrm{H}_{2}^{+}+\mathrm{H}_{2} \rightarrow \mathrm{H}_{3}^{+}+\mathrm{H}$, so that $\mathrm{H}_{3}^{+}$becomes the dominant ion in all the scenarios considered. We also found that after $4 \mathrm{~ms}$, the concentration of the positive ion $\mathrm{He}^{+}$becomes the second largest (after $\mathrm{H}_{3}^{+}$) when we use $M=10^{5} \mathrm{C} \mathrm{km}$ with profiles (a) and $M=10^{6} \mathrm{C} \mathrm{km}$ with profile (b). The maximum total number of UV and Fulcher photons from a possible saturnian halo predicted with our full kinetic model are, respectively, $10^{25}$ and $10^{24}$ when $M=10^{6} \mathrm{C} \mathrm{km}$ and profile (b) are used.

Our analysis in Section 2 shows that $M=10^{6} \mathrm{C} \mathrm{km}$ can fit the observed discharge energy $\left(\sim 10^{12}-10^{13} \mathrm{~J}\right)$, but only if the lightning channel is long, of the order of a hundred kilometers, otherwise the uniform charge cells would overlap. Whether such a large separation is possible remains to be determined; either by detailed modeling which includes cloud microphysics, or by new observations. It seems that detectable halos are unlikely in Saturn's atmosphere, but there is a possibility of sprites if the conventional breakdown field is exceeded below the transition altitude. The altitude of the event above the cloud tops could be estimated if images are taken toward the planet's limb. The lower boundary of a halo can be used to estimate the transition altitude. Such observations could be used to probe the local electron density.

\section{Acknowledgments}

We would like to thank G. Fischer for his helpful input on saturnian lightning. We wish to thank the anonymous reviewers for their in-depth comments.

The work of DD and YY is supported by the Israeli Ministry of Science scholarship in Memory of Col. Ilan Ramon, the Research Authority of the Open University of Israel, and by the Israeli Science Foundation Grant 117/09. Cooperation was facilitated by the support of the European Science Foundation, Grant No. 5269. The work by AL, FJGV and FCPR is supported by the Spanish Ministry of Science and Innovation, MINECO under project AYA201129936-C05-02 and by the Junta de Andalucia under Proyecto de Excelencia FQM-5965. AL is supported by a Ramón y Cajal contract, Code RYC-2011-07801 and FCPR acknowledges MINECO for a FPI Grant, Code BES-2010-042367.

\section{Appendix A}

The 32 species included in the global kinetic model

\begin{tabular}{l}
\hline Species \\
\hline $\mathrm{H}_{2}\left(\mathrm{X}^{1} \Sigma_{\mathrm{g}}^{+}, v=0\right), \mathrm{He}, \mathrm{H}$ \\
$\mathrm{H}_{2}\left(\mathrm{~B}^{1} \Sigma_{\mathrm{u}}^{+}, \mathrm{c}^{3} \Pi_{\mathrm{u}}, \mathrm{a}^{3} \Sigma_{\mathrm{g}}^{+}, \mathrm{C}^{1} \Pi_{\mathrm{u}}, \mathrm{d}^{3} \Pi_{\mathrm{u}}\right)$ \\
$\mathrm{H}_{2}\left(\mathrm{X}^{1} \Sigma_{\mathrm{g}}^{+}(v=1, \ldots, 9)\right)$ \\
$\mathrm{H}\left(2 \mathrm{~s}^{2} \mathrm{~S}\right), \mathrm{H}\left(2 \mathrm{p}{ }^{2} \mathrm{P}\right), \mathrm{H}(3), \mathrm{H}(4), \mathrm{H}(5)$ \\
$\mathrm{He}\left(2 \mathrm{~s}^{2}{ }^{3} \mathrm{~S}\right), \mathrm{He}_{2}\left(\mathrm{a}^{3} \Sigma_{\mathrm{u}}^{+}\right)$ \\
$\mathrm{e}^{-}, \mathrm{H}^{-}$ \\
$\mathrm{H}^{+}, \mathrm{H}_{2}^{+}, \mathrm{H}_{3}^{+}, \mathrm{H}_{\mathrm{e}}^{+}, \mathrm{He}_{2}^{+}, \mathrm{HeH}^{+}$ \\
\hline
\end{tabular}

\section{Appendix B}

Reactions and rate coefficients associated with the electron driven kinetics and heavy particle chemistry. The rata coefficients for the electron-impact processes are evaluated using the calculated electron energy distribution function (EEDF) and the corresponding cross sections. When cross sections are not available, the rates of electronic processes are given as $k_{e}=a \times T_{e}^{b} \times \exp \left(-c / T_{e}\right)$ where $T_{e}$ (in $\mathrm{eV}$ ) is the "electron temperature". The rate coefficients for 
the kinetic mechanisms involving heavy particles (neutrals and ions) are parameterized as $k_{h}=d \times\left(T_{g} / 300\right)^{e} \times \exp \left(-f / T_{g}\right)$ with $T_{g}$ (in $\mathrm{K}$ ) being the ambient gas temperature. The units of $k_{e, h}$ are $\mathrm{cm}^{3} \mathrm{~s}^{-1}$ and $\mathrm{cm}^{6} \mathrm{~s}^{-1}$ for two- and three-body reactions, respectively. The units of $a$ and $d$ are $\mathrm{cm}^{3} \mathrm{~s}^{-1}$ (two body reactions) or $\mathrm{cm}^{6} \mathrm{~s}^{-1}$ (three body reactions); $b$ and $e$ are non-dimensional parameters, and the units of $c$ and $f$ are $\mathrm{eV}$ and Kelvin (K), respectively. For radiative processes, the magnitudes $A\left(\mathrm{~s}^{-1}\right), \lambda$ (nm) and $\kappa$ stand for the Einstein coefficient of spontaneous radiative de-excitation, emission wavelength and optical thickness $(0 \leqslant \kappa \leqslant 1)$ assumed. The reference sources of the cross sections and/or rates used are indicated in the last column of each of the tables below. The initials CS that appears in the tables below stand for cross section.

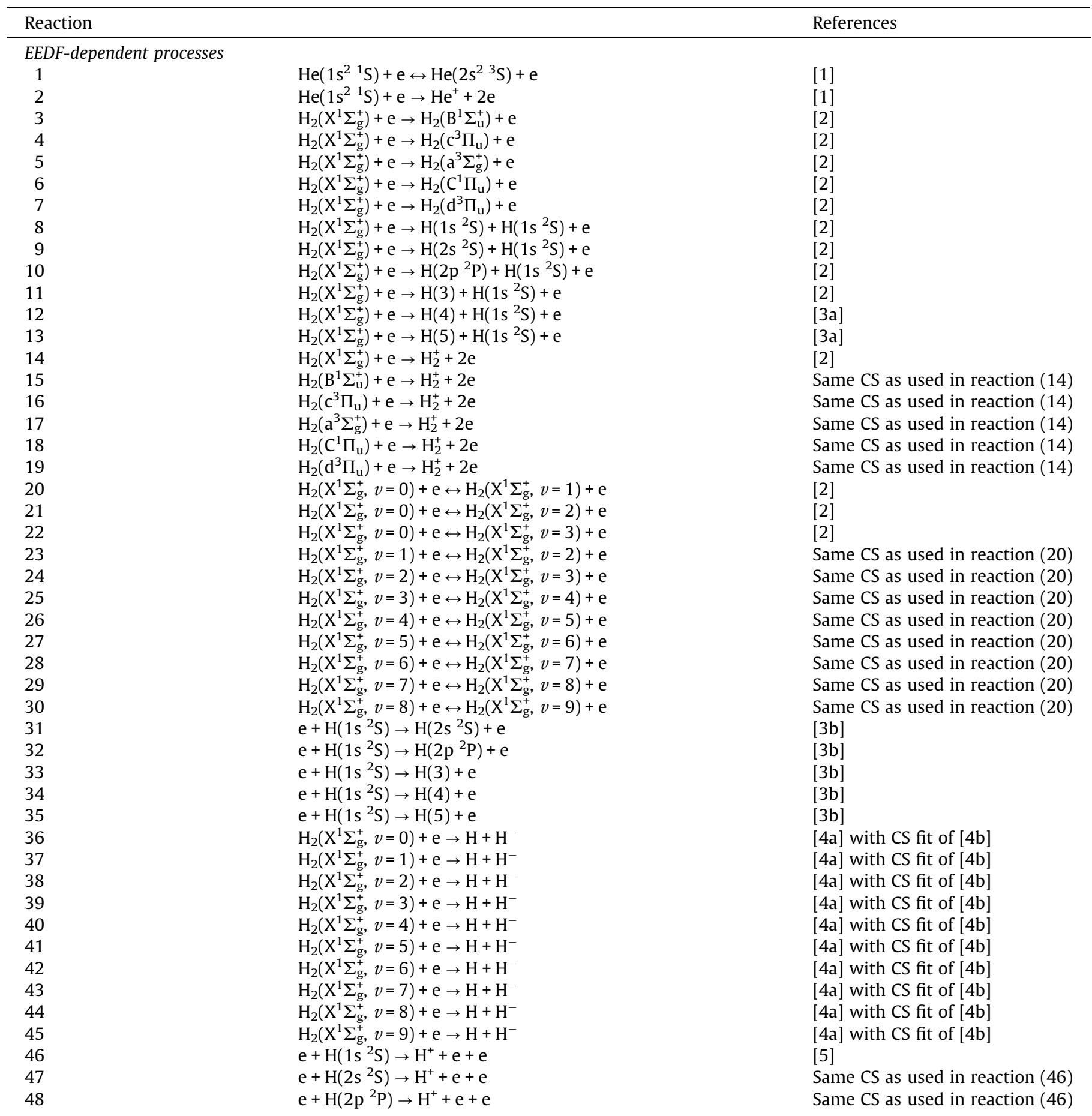


Appendix B (continued)

\begin{tabular}{|c|c|c|c|c|c|}
\hline Reaction & & $\mathrm{a}$ & $\mathrm{b}$ & c & References \\
\hline \multicolumn{6}{|c|}{ Te-dependent processes: ionization } \\
\hline 49 & $\mathrm{e}+\mathrm{He}_{2}^{*} \rightarrow \mathrm{He}_{2}^{+}+\mathrm{e}+\mathrm{e}$ & $9.75 \mathrm{e}-10$ & 0.71 & 3.4 & {$[6]$} \\
\hline \multicolumn{6}{|c|}{ Te-dependent processes: dissociation } \\
\hline 50 & $\mathrm{e}+\mathrm{H}_{2} \rightarrow \mathrm{H}+\mathrm{H}+\mathrm{e}$ & $1.7527 \mathrm{e}-7$ & -1.2366 & 12.5924 & [7] \\
\hline 51 & $\mathrm{e}+\mathrm{H}_{2}^{+} \rightarrow \mathrm{H}^{+}+\mathrm{H}+\mathrm{e}$ & $1.0702 \mathrm{e}-7$ & 0.04876 & 9.69028 & [7] \\
\hline 52 & $\mathrm{e}+\mathrm{H}_{2}^{+} \rightarrow \mathrm{H}^{+}+\mathrm{H}^{+}+2 \mathrm{e}$ & $2.1202 \mathrm{e}-9$ & 0.31394 & 23.2988 & [7] \\
\hline 53 & $\mathrm{e}+\mathrm{H}_{3}^{+} \rightarrow \mathrm{H}_{2}^{+}+\mathrm{H}+\mathrm{e}$ & $4.8462 \mathrm{e}-7$ & -0.04975 & 19.1656 & [7] \\
\hline 54 & $\mathrm{e}+\mathrm{He}_{2}\left(\mathrm{a}^{3} \Sigma_{\mathrm{u}}^{+}\right) \rightarrow \mathrm{e}+\mathrm{He}+\mathrm{He}$ & $3.8 \mathrm{e}-9$ & & & [6] \\
\hline \multicolumn{6}{|c|}{ Te-dependent processes: attachment and dissociative attachment } \\
\hline 55 & $\mathrm{e}+\mathrm{H} \rightarrow \mathrm{H}^{-}$ & $3.46 \mathrm{e}-16$ & 0.5 & & {$[6]$} \\
\hline 56 & $\mathrm{e}+\mathrm{H}_{2}^{+} \rightarrow \mathrm{H}^{+}+\mathrm{H}^{-}$ & $2.17 \mathrm{e}-10$ & -0.2 & 0.2 & {$[6]$} \\
\hline \multicolumn{6}{|c|}{ Te-dependent processes: excitation/de-excitation } \\
\hline 57 & $\mathrm{e}+\mathrm{H}\left(2 \mathrm{~s}^{2} \mathrm{~S}\right) \rightarrow \mathrm{H}\left(2 \mathrm{p}^{2} \mathrm{P}\right)+\mathrm{e}$ & $6 . e-5$ & & & {$[8]$} \\
\hline 58 & $\mathrm{e}+\mathrm{H}\left(2 \mathrm{p}^{2} \mathrm{P}\right) \rightarrow \mathrm{H}\left(2 \mathrm{~s}^{2} \mathrm{~S}\right)+\mathrm{e}$ & $2 . e-5$ & & & {$[8]$} \\
\hline 59 & $\mathrm{e}+\mathrm{H}\left(2 \mathrm{~s}^{2} \mathrm{~S}\right) \rightarrow \mathrm{e}+\mathrm{H}(3)$ & $1.68 \mathrm{e}-6$ & 0.1013 & 1.9 & [6] \\
\hline 60 & $\mathrm{e}+\mathrm{H}\left(2 \mathrm{p}^{2} \mathrm{P}\right) \rightarrow \mathrm{e}+\mathrm{H}(3)$ & $1.68 \mathrm{e}-6$ & 0.1013 & 1.9 & {$[6]$} \\
\hline \multicolumn{6}{|c|}{ Te-dependent processes: detachment } \\
\hline 61 & $\mathrm{e}+\mathrm{H}^{-} \rightarrow \mathrm{e}+\mathrm{e}+\mathrm{H}$ & $2.32 \mathrm{e}-8$ & 2.0 & 0.13 & {$[6]$} \\
\hline \multicolumn{6}{|c|}{ Te-dependent processes: recombination and dissociative recombination } \\
\hline 62 & $\mathrm{e}+\mathrm{H}_{2}^{+} \rightarrow \mathrm{H}+\mathrm{H}(3)$ & $5.33 e-8$ & -0.4 & & [9] \\
\hline 63 & $\mathrm{e}+\mathrm{H}_{2}^{+} \rightarrow \mathrm{H}+\mathrm{H}\left(2 \mathrm{~s}^{2} \mathrm{~S}\right)$ & $0.21 \mathrm{e}-8$ & -0.4 & & [9] \\
\hline 64 & $\mathrm{e}+\mathrm{H}_{3}^{+} \rightarrow \mathrm{H}+\mathrm{H}+\mathrm{H}$ & $0.75 e-8$ & -0.8 & & [9] \\
\hline 65 & $\mathrm{e}+\mathrm{H}_{3}^{+} \rightarrow \mathrm{H}_{2}+\mathrm{H}$ & $0.75 e-8$ & -0.8 & & [9] \\
\hline 66 & $\mathrm{e}+\mathrm{He}_{2}^{+} \rightarrow \mathrm{He}\left(2 \mathrm{~s}^{2}{ }^{3} \mathrm{~S}\right)+\mathrm{He}$ & $5.38 \mathrm{e}-11$ & -1 & & {$[10]$} \\
\hline 67 & $\mathrm{e}+\mathrm{He}^{+} \rightarrow \mathrm{He}\left(2 \mathrm{~s}^{2}{ }^{3} \mathrm{~S}\right)$ & $6.76 e-13$ & -0.5 & & {$[6]$} \\
\hline 68 & $2 \mathrm{e}+\mathrm{He}^{+} \rightarrow \mathrm{He}\left(2 \mathrm{~s}^{2}{ }^{3} \mathrm{~S}\right)+\mathrm{e}$ & $1.31 \mathrm{e}-28$ & -4.4 & & [6] \\
\hline 69 & $\mathrm{e}+\mathrm{He}^{+}+\mathrm{He} \rightarrow \mathrm{He}\left(2 \mathrm{~s}^{2}{ }^{3} \mathrm{~S}\right)+\mathrm{He}$ & $1.15 \mathrm{e}-30$ & -2.0 & & [6] \\
\hline 70 & $2 \mathrm{e}+\mathrm{He}_{2}^{+} \rightarrow \mathrm{He}\left(2 \mathrm{~s}^{2}{ }^{3} \mathrm{~S}\right)+\mathrm{He}+\mathrm{e}$ & $2.80 \mathrm{e}-20$ & & & {$[6]$} \\
\hline 71 & $2 \mathrm{e}+\mathrm{He}_{2}^{+} \rightarrow \mathrm{He}_{2}\left(\mathrm{a}^{3} \Sigma_{\mathrm{u}}^{+}\right)+\mathrm{e}$ & $1.20 \mathrm{e}-21$ & & & {$[6]$} \\
\hline 72 & $\mathrm{e}+\mathrm{He}_{2}^{+}+\mathrm{He} \rightarrow \mathrm{He}\left(2 \mathrm{~s}^{2}{ }^{3} \mathrm{~S}\right)+2 \mathrm{He}$ & $3.50 \mathrm{e}-27$ & & & [6] \\
\hline 73 & $\mathrm{e}+\mathrm{He}_{2}^{+}+\mathrm{He} \rightarrow \mathrm{He}_{2}\left(\mathrm{a}^{3} \Sigma_{\mathrm{u}}^{+}\right)+\mathrm{He}$ & $1.50 \mathrm{e}-27$ & & & {$[6]$} \\
\hline 74 & $\mathrm{e}+\mathrm{HeH}^{+} \rightarrow \mathrm{H}+\mathrm{He}$ & $1.10 \mathrm{e}-9$ & -0.6 & & {$[6]$} \\
\hline 75 & $\mathrm{e}+\mathrm{H}^{+} \rightarrow \mathrm{H}$ & $2.62 \mathrm{e}-13$ & -0.5 & & {$[6]$} \\
\hline 76 & $2 \mathrm{e}+\mathrm{H}^{+} \rightarrow \mathrm{e}+\mathrm{H}$ & $8.8 \mathrm{e}-27$ & -4.5 & & {$[6]$} \\
\hline 77 & $\mathrm{e}+\mathrm{H}_{3}^{+} \rightarrow \mathrm{e}+\mathrm{H}^{+}+2 \mathrm{H}$ & $1.8 \mathrm{e}-8$ & 0.95 & 10.5 & {$[6]$} \\
\hline
\end{tabular}

Reaction

d

e

f

References

Heavy particle chemistry: ground neutrals

$\begin{array}{ll}78 & 2 \mathrm{H} \rightarrow \mathrm{H}_{2} \\ 79 & 2 \mathrm{H}+\mathrm{He} \rightarrow \mathrm{H}_{2}+\mathrm{He} \\ 80 & 3 \mathrm{H} \rightarrow \mathrm{H}+\mathrm{H}_{2} \\ 81 & 2 \mathrm{H}+\mathrm{H}_{2} \rightarrow 2 \mathrm{H}_{2}\end{array}$

$6.04 \mathrm{e}-33$

$5.80 \mathrm{e}-33$

$6.00 \mathrm{e}-31$

$8.10 \mathrm{e}-33$

-1
-1
-1
-0.6

[6]

[6]

Heavy particle chemistry: electronically excited neutrals including Penning ionization

$\begin{array}{lll}82 & \mathrm{H}_{2}\left(\mathrm{~d}^{3} \Pi_{\mathrm{u}}\right)+\mathrm{H}_{2} \rightarrow \mathrm{H}_{2}\left(\mathrm{a}^{3} \Sigma_{\mathrm{g}}^{+}\right)+\mathrm{H}_{2} & 1.2 \mathrm{e}-9 \\ 83 & \mathrm{H}_{2}\left(\mathrm{a}^{3} \Sigma_{\mathrm{g}}^{+}\right)+\mathrm{H}_{2} \rightarrow \mathrm{H}_{2}+\mathrm{H}_{2} & 1.7 \mathrm{e}-10 \\ 84 & \mathrm{He}\left(2 \mathrm{~s}^{2} \mathrm{~S}\right)+2 \mathrm{He} \rightarrow \mathrm{He}_{2}\left(\mathrm{a}^{3} \Sigma_{\mathrm{u}}^{+}\right)+\mathrm{He} & 2.00 \mathrm{e}-34 \\ 85 & \mathrm{He}_{2}\left(\mathrm{a}^{3} \Sigma_{\mathrm{u}}^{+}\right)+\mathrm{H}_{2} \rightarrow 2 \mathrm{He}+\mathrm{H}_{2} & 1.50 \mathrm{e}-15 \\ 86 & \mathrm{He}\left(2 \mathrm{~s}^{2} \mathrm{~S}\right)+\mathrm{H}_{2} \rightarrow \mathrm{H}\left(2 \mathrm{p}{ }^{2} \mathrm{P}\right)+\mathrm{H}+\mathrm{He} & 1.40 \mathrm{e}-11 \\ 87 & \mathrm{He}+\mathrm{H}(3) \rightarrow \mathrm{H}+\mathrm{He} & 1.00 \mathrm{e}-11 \\ 88 & \mathrm{H}\left(2 \mathrm{p}{ }^{2} \mathrm{P}\right)+\mathrm{H}_{2} \rightarrow 3 \mathrm{H} & 2.1 \mathrm{e}-11 \\ 89 & \mathrm{H}\left(2 \mathrm{~s}^{2} \mathrm{~S}\right)+\mathrm{H}_{2} \rightarrow 3 \mathrm{H} & 2.1 \mathrm{e}-11 \\ 90 & \mathrm{H}(3)+\mathrm{H}_{2} \rightarrow \mathrm{H}+\mathrm{H}_{2} & 2.0 \mathrm{e}-9 \\ 91 & \mathrm{He}\left(2 \mathrm{~s}^{2}{ }^{3} \mathrm{~S}\right)+\mathrm{He}\left(2 \mathrm{~s}^{2}{ }^{3} \mathrm{~S}\right) \rightarrow \mathrm{He}+\mathrm{He}^{+}+\mathrm{e} & 8.7 \mathrm{e}-10 \\ 92 & \mathrm{He}\left(2 \mathrm{~s}^{2}{ }^{3} \mathrm{~S}\right)+\mathrm{He}\left(2 \mathrm{~s}^{2}{ }^{3} \mathrm{~S}\right) \rightarrow \mathrm{He}_{2}^{+}+\mathrm{e} & 2.03 \mathrm{e}-9 \\ 93 & \mathrm{He}\left(2 \mathrm{~s}^{2}{ }^{3} \mathrm{~S}\right)+\mathrm{He} \mathrm{e}_{2}\left(\mathrm{a}^{3} \Sigma_{\mathrm{u}}^{+}\right) \rightarrow \mathrm{He}^{+}+2 \mathrm{He}+\mathrm{e} & 5.0 \mathrm{e}-10 \\ 94 & \mathrm{He}\left(2 \mathrm{~s}^{2}{ }^{3} \mathrm{~S}\right)+\mathrm{He} 2\left(\mathrm{a}^{3} \Sigma_{\mathrm{u}}^{+}\right) \rightarrow \mathrm{He}_{2}^{+}+\mathrm{He}+\mathrm{e} & 2.0 \mathrm{e}-9 \\ 95 & \mathrm{He}\left(2 \mathrm{~s}^{2}{ }^{3} \mathrm{~S}\right)+\mathrm{H} \rightarrow \mathrm{H}^{+}+\mathrm{He}+\mathrm{e} & 1.1 \mathrm{e}-9\end{array}$

[6] 
Appendix B (continued)

\begin{tabular}{lllll}
\hline Reaction & & $\mathrm{d}$ & $\mathrm{e}$ & $\mathrm{f}$ \\
\hline 96 & $\mathrm{He}\left(2 \mathrm{~s}^{2}{ }^{3} \mathrm{~S}\right)+\mathrm{H}_{2} \rightarrow \mathrm{H}_{2}^{+}+\mathrm{He}+\mathrm{e}$ & $2.9 \mathrm{e}-11$ & References \\
97 & $\mathrm{He}\left(2 \mathrm{~s}^{2}{ }^{3} \mathrm{~S}\right)+\mathrm{H}_{2} \rightarrow \mathrm{H}+\mathrm{HeH}^{+}+\mathrm{e}$ & $3.0 \mathrm{e}-12$ & & {$[6]$} \\
98 & $2 \mathrm{He}_{2}\left(\mathrm{a}^{3} \Sigma_{\mathrm{u}}^{+}\right) \rightarrow \mathrm{He}^{+}+3 \mathrm{He}+\mathrm{e}$ & $3.0 \mathrm{e}-10$ & & {$[6]$} \\
99 & $2 \mathrm{He}_{2}\left(\mathrm{a}^{3} \Sigma_{\mathrm{u}}^{+}\right) \rightarrow \mathrm{He}_{2}^{+}+2 \mathrm{He}+\mathrm{e}$ & $1.2 \mathrm{e}-9$ & {$[6]$} \\
100 & $\mathrm{He}_{2}\left(\mathrm{a}^{3} \Sigma_{\mathrm{u}}^{+}\right)+\mathrm{H} \rightarrow 2 \mathrm{He}+\mathrm{H}^{+}+\mathrm{e}$ & $2.2 \mathrm{e}-10$ & {$[6]$} \\
101 & $\mathrm{He}_{2}\left(\mathrm{a}^{3} \Sigma_{\mathrm{u}}^{+}\right)+\mathrm{H}_{2} \rightarrow \mathrm{H}_{2}^{+}+2 \mathrm{He}+\mathrm{e}$ & $2.2 \mathrm{e}-10$ & & {$[6]$} \\
\end{tabular}

Heavy particle chemistry: vibrational-vibrational processes

$\begin{array}{llll}102 & \mathrm{H}_{2}(v=1)+\mathrm{H}_{2}(v=1) \rightarrow \mathrm{H}_{2}(v=2)+\mathrm{H}_{2} & 9.3 \mathrm{e}-15 \\ 103 & \mathrm{H}_{2}(v=1)+\mathrm{H}_{2}(v=2) \rightarrow \mathrm{H}_{2}(v=3)+\mathrm{H}_{2} & 1.7 \mathrm{e}-14 \\ 104 & \mathrm{H}_{2}(v=1)+\mathrm{H}_{2}(v=3) \rightarrow \mathrm{H}_{2}(v=4)+\mathrm{H}_{2} & 2.6 \mathrm{e}-14 \\ 105 & \mathrm{H}_{2}(v=1)+\mathrm{H}_{2}(v=4) \rightarrow \mathrm{H}_{2}(v=5)+\mathrm{H}_{2} & 3.3 \mathrm{e}-14 \\ 106 & \mathrm{H}_{2}(v=1)+\mathrm{H}_{2}(v=5) \rightarrow \mathrm{H}_{2}(v=6)+\mathrm{H}_{2} & 3.2 \mathrm{e}-14 \\ 107 & \mathrm{H}_{2}(v=1)+\mathrm{H}_{2}(v=6) \rightarrow \mathrm{H}_{2}(v=7)+\mathrm{H}_{2} & 2.5 \mathrm{e}-14 \\ 108 & \mathrm{H}_{2}(v=1)+\mathrm{H}_{2}(v=7) \rightarrow \mathrm{H}_{2}(v=8)+\mathrm{H}_{2} & 1.6 \mathrm{e}-14 \\ 109 & \mathrm{H}_{2}(v=1)+\mathrm{H}_{2}(v=8) \rightarrow \mathrm{H}_{2}(v=9)+\mathrm{H}_{2} & 9.5 \mathrm{e}-15\end{array}$

Heavy particle chemistry: vibrational-translational processes

$\begin{array}{ll}110 & \mathrm{H}_{2}(v=1)+\mathrm{H}_{2} \rightarrow \mathrm{H}_{2}+\mathrm{H}_{2} \\ 111 & \mathrm{H}_{2}(v=2)+\mathrm{H}_{2} \rightarrow \mathrm{H}_{2}(v=1)+\mathrm{H}_{2} \\ 112 & \mathrm{H}_{2}(v=3)+\mathrm{H}_{2} \rightarrow \mathrm{H}_{2}(v=2)+\mathrm{H}_{2} \\ 113 & \mathrm{H}_{2}(v=4)+\mathrm{H}_{2} \rightarrow \mathrm{H}_{2}(v=3)+\mathrm{H}_{2} \\ 114 & \mathrm{H}_{2}(v=5)+\mathrm{H}_{2} \rightarrow \mathrm{H}_{2}(v=4)+\mathrm{H}_{2} \\ 115 & \mathrm{H}_{2}(v=6)+\mathrm{H}_{2} \rightarrow \mathrm{H}_{2}(v=5)+\mathrm{H}_{2} \\ 116 & \mathrm{H}_{2}(v=7)+\mathrm{H}_{2} \rightarrow \mathrm{H}_{2}(v=6)+\mathrm{H}_{2} \\ 117 & \mathrm{H}_{2}(v=8)+\mathrm{H}_{2} \rightarrow \mathrm{H}_{2}(v=7)+\mathrm{H}_{2} \\ 118 & \mathrm{H}_{2}(v=9)+\mathrm{H}_{2} \rightarrow \mathrm{H}_{2}(v=8)+\mathrm{H}_{2}\end{array}$

$1.6 e-16$

$7.8 \mathrm{e}-16$

$3.0 \mathrm{e}-15$

$1.0 \mathrm{e}-14$

$3.2 \mathrm{e}-14$

$1.0 \mathrm{e}-13$

$3.3 e-13$

$1.1 \mathrm{e}-12$

$3.3 e-12$

Ionic chemistry: ion-ion recombination

$\begin{array}{ll}119 & \mathrm{H}^{-}+\mathrm{H}^{+} \rightarrow \mathrm{H}+\mathrm{H} \\ 120 & \mathrm{He}^{+}+\mathrm{H}^{-} \rightarrow \mathrm{H}+\mathrm{He} \\ 121 & \mathrm{HeH}^{+}+\mathrm{H}^{-} \rightarrow \mathrm{H}_{2}+\mathrm{He} \\ 122 & \mathrm{He}_{2}^{+}+\mathrm{H}^{-} \rightarrow \mathrm{H}+2 \mathrm{He} \\ 123 & \mathrm{H}^{+}+\mathrm{H}^{-} \rightarrow \mathrm{H}\left(2 \mathrm{~s}^{2} \mathrm{~S}\right)+\mathrm{H} \\ 124 & \mathrm{H}^{+}+\mathrm{H}^{-} \rightarrow \mathrm{H}\left(2 \mathrm{p}{ }^{2} \mathrm{P}\right)+\mathrm{H} \\ 125 & \mathrm{H}^{+}+\mathrm{H}^{-} \rightarrow \mathrm{H}(3)+\mathrm{H} \\ 126 & \mathrm{H}_{2}^{+}+\mathrm{H}^{-} \rightarrow \mathrm{H}+\mathrm{H}_{2} \\ 127 & \mathrm{H}_{3}^{+}+\mathrm{H}^{-} \rightarrow 2 \mathrm{H}_{2}\end{array}$

$3.900 \mathrm{e}-07$

$2.3 e-7$

$1.0 \mathrm{e}-7$

$1.0 \mathrm{e}-7$

$9.0 \mathrm{e}-11$

$9.0 \mathrm{e}-11$

[6]

[6]

$1.8 \mathrm{e}-7$

$2.0 \mathrm{e}-7$

$-0.5$

[6]

0.83

[6]

[6]

$2.0 \mathrm{e}-7$

[6]

[6]

[6]

Ionic chemistry: positive ions

$\begin{array}{ll}128 & \mathrm{H}^{+}+\mathrm{H}_{2} \rightarrow \mathrm{H}_{2}^{+}+\mathrm{H} \\ 129 & \mathrm{H}_{2}^{+}+\mathrm{H} \rightarrow \mathrm{H}^{+}+\mathrm{H}_{2} \\ 130 & \mathrm{H}_{2}^{+}+\mathrm{H}_{2} \rightarrow \mathrm{H}_{3}^{+}+\mathrm{H} \\ 131 & \mathrm{He}^{+}+2 \mathrm{He} \rightarrow \mathrm{He}_{2}^{+}+\mathrm{He} \\ 132 & \mathrm{He}^{+}+\mathrm{H} \rightarrow \mathrm{H}^{+}+\mathrm{He} \\ 133 & \mathrm{He}^{+}+\mathrm{H} \rightarrow \mathrm{HeH}^{+} \\ 134 & \mathrm{He}^{+}+\mathrm{H}_{2} \rightarrow \mathrm{H}^{+}+\mathrm{H}+\mathrm{He} \\ 135 & \mathrm{He}^{+}+\mathrm{H}_{2} \rightarrow \mathrm{H}_{2}^{+}+\mathrm{He} \\ 136 & \mathrm{HeH}^{+}+\mathrm{H} \rightarrow \mathrm{H}_{2}^{+}+\mathrm{He} \\ 137 & \mathrm{HeH}^{+}+\mathrm{H}_{2} \rightarrow \mathrm{H}_{3}^{+}+\mathrm{He} \\ 138 & \mathrm{He}_{2}^{+}+\mathrm{H} \rightarrow \mathrm{H}^{+}+2 \mathrm{He} \\ 139 & \mathrm{He}_{2}^{+}+\mathrm{H}_{2} \rightarrow \mathrm{HeH}^{+}+\mathrm{H}+\mathrm{He} \\ 140 & \mathrm{H}^{+}+\mathrm{He} \rightarrow \mathrm{HeH}^{+} \\ 141 & \mathrm{H}^{+}+\mathrm{H}+\mathrm{H}_{2} \rightarrow \mathrm{H}_{2}^{+}+\mathrm{H} \\ 142 & \mathrm{H}^{+}+\mathrm{H}_{2}+\mathrm{He}_{3} \rightarrow \mathrm{H}_{3}^{+}+\mathrm{He} \\ 143 & \mathrm{H}_{2}^{+}+\mathrm{He} \rightarrow \mathrm{HeH}^{+}+\mathrm{H}\end{array}$

$1.19 \mathrm{e}-22$

[7]

$6.4 \mathrm{e}-10$

$2.0 \mathrm{e}-9$

[14]

$1.4 \mathrm{e}-31$

$-0.6$

[10]

$1.9 \mathrm{e}-15$

[6]

$1.58 \mathrm{e}-15$

$-0.3$

$3.7 \mathrm{e}-14$

[6]

$7.2 \mathrm{e}-15$

$9.1 \mathrm{e}-10$

$1.5 \mathrm{e}-9$

$3.5 \mathrm{e}-10$

$1.76 \mathrm{e}-10$

$8.4 \mathrm{e}-19$

$1.0 \mathrm{e}-34$

$1.5 \mathrm{e}-29$

$1.3 \mathrm{e}-10$

[6]

[6]

[6]

[6]

[6]

[6]

[6]

[6]

[6]

[6]

Ionic chemistry: negative ions

$\begin{array}{ll}144 & \mathrm{H}^{-}+\mathrm{H} \rightarrow \mathrm{H}_{2}+\mathrm{e} \\ 145 & \mathrm{H}^{-}+\mathrm{He} \rightarrow \mathrm{He}+\mathrm{H}+\mathrm{e}\end{array}$

$1.800 \mathrm{e}-9$

[14]

8.e-12

0.5

[6] 
Appendix B (continued)

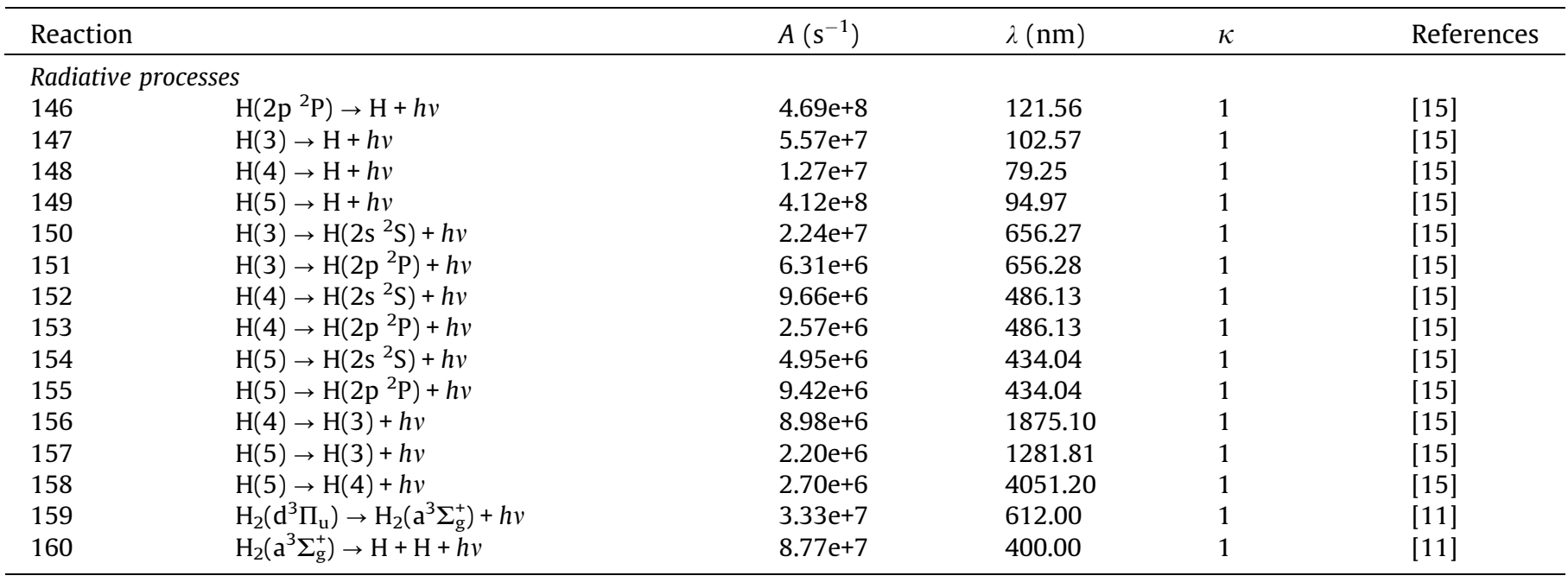

[1] Helium IST-Lisbon Electron Impact Cross Section Database in LxCat. <www.lxcat.laplace.univ-tlse-fr〉.

[2] $\mathrm{H}_{2}$ Phelps Electron Impact Cross Section Database in LxCat. <www.lxcat.laplace.univ-tlse-fr>.

[3a] $\mathrm{H}_{2}$ IST-Lisbon Electron Impact Cross Section Database in LxCat. <www.lxcat.laplace.univ-tlse-fr>.

[3b] H IST-Lisbon Electron Impact Cross Section Database in LxCat. <www.lxcat.laplace.univ-tlse-fr>.

[4a] Bardsley, J.N., Wadehra, J.M., 1979. Phys. Rev. A 20, 1398.

[4b] Celiberto, R., Janev, R.K., Laricchiuta, A., Capitelli, M., Wadehra, J.M., Atems, D.E., 2001. Atom. Data Nucl. Tables 77(2), $161-213$.

[5] I. Bray's Electron Impact Cross Section Database. <http://atom.curtin.edu.au/CCC-WWW/>.

[6] Liu, D.X., Bruggeman, P., Iza, F., Rong, M.Z., Kong, M.G., 2010. Plasma Sour. Sci. Technol. 19, 025018.

[7] Méndez, I., Gordillo-Vázquez, F.J., Herrero, V., Tanarro, I., 2006. J. Phys. Chem. A 110, 6060.

[8] Seaton, M.J., 1955. Proc. Phys. Soc. (London) 68, 457.

[9] Mitchell, J.B.A., 1990. Phys. Rep. 186, 216.

[10] Alves, L.L., Gousset, G., Ferreira, C.M., 1992. J. Phys. D: Appl. Phys. 25, 1713.

[11] Bretagne, J., Godart, J., Puech, V., 1981. J. Phys. B: Atom. Mol. Phys. 14, L761.

[12] Capitelli, M., Celiberto, R., Cacciatore, M., 1994. Adv. Atom. Mol. Opt. Phys. 33, 321.

[13] Fridman, A., 2008. Plasma Chemistry, Cambridge University Press.

[14] Capitelli, M., Ferreira, C.M., Gordiets, B.F., Osipov, A.I., 2000. Plasma Kinetics in Atmospheric Gases. Springer, Berlin.

[15] Wiese, W.L., Smith, M.W., Glennon, B.M., 1966. Atomic Transition Probabilities, vol. 1. NSRDS-NBS 4, Washington DC.

\section{Appendix C}

In this appendix, we show that the total amount of electrons liberated and photons produced during the Maxwell relaxation of an atmospheric volume is independent of the initial electron density if the external electric field varies slowly in time during the screening process. This is a generalization of the argument exposed in Li et al. (2007) where it was applied to the calculation of ionization in a streamer head. Although this result may appear counterintuitive, its underlying reason is that when the initial electron density is higher, the faster relaxation exactly compensates the increased frequency of impact ionization or excitation.

Under the assumption that the externally applied field varies slowly and the geometry is close to planar, a local field undergoes Maxwell relaxation and decays exponentially following Eq. (7) in Section 5, with $E_{p}=0$ :

$\frac{d E}{d t}=-\frac{\sigma}{\epsilon_{0}} E=-\frac{e \mu_{e} N_{e}}{\epsilon_{0}} E$.

Now consider any two-body process involving electrons and an abundant species. The most important cases are ionization:

$\mathrm{e}+\mathrm{H}_{2} \rightarrow 2 \mathrm{e}+\mathrm{H}_{2}^{+}$

and impact excitation,

$\mathrm{e}+\mathrm{H}_{2} \rightarrow \mathrm{e}+\mathrm{H}_{2}^{*}$.

These processes can be described by equations of the form

$\frac{d N_{X}}{d t}=v(E / N) N_{e}$, where $N_{X}$ is the density of the species that we are interested in, like $N_{e}$ for ionization or the density of $\mathrm{H}_{2}^{-}$or $\mathrm{H}_{2}^{*}$. Dividing (C4) by (C1) we see that the $N_{e}$ on the right hand sides cancel and the variables $E$ and $N_{X}$ can be separated:

$\frac{d N_{X}}{d E}=-\frac{\epsilon_{0} v}{e \mu_{e} E}$.

This can be integrated to yield

$N_{X}(t)-N_{X}(0)=-\frac{\epsilon_{0}}{e} \int_{E(0)}^{E(t)} \frac{v d E}{\mu_{e} E}$

After a long time, the electric field is fully relaxed $(E(t) \rightarrow 0)$ and the increase in $N_{X}$ is independent on the initial electron density.

\section{References}

Astashkevich, S., Lavrov, B., 2002. Lifetimes of the electronic-vibrational-rotational states of hydrogen molecule (review). Opt. Spectrosc. 92 (6), 818-850.

Atreya, S.K., 1986. Atmospheres and Ionospheres of the Outer Planets and Their Satellites, vol. 15. Springer Verlag, Springer Series on Physics Chemistry Space.

Atreya, S.K., Wong, A.-S., 2005. Coupled clouds and chemistry of the giant planets A case for multiprobes. Space Sci. Rev. 116 (1-2), 121-136.

Bardsley, J., Wadehra, J., 1979. Dissociative attachment and vibrational excitation in low-energy collisions of electrons with $\mathrm{H}_{2}$ and $\mathrm{D}_{2}$. Phys. Rev. A 20 (4), 13981405.

Bretagne, J., Godart, J., Puech, V., 1981. Time-resolved study of the $\mathrm{H}_{2}$ continuum at low pressures. J. Phys. B: Atom. Mol. Phys. 14, L761-L765.

Bruce, C., Golde, R., 1941. The lightning discharge. Electric. Eng. - Part II: Power Eng., J. Inst. IET 88, 487-505.

Buckman, S.J., Phelps, A.V., 1985. JILA information center report no. 27, University of Colorado. J. Chem. Phys. 82, 4999-5011, www.lxcat.net.

Celiberto, R., Janev, R.K., Laricchiuta, A., Capitelli, M., Wadehra, J.M., Atems, D.E., 2001. Cross section data for electron-impact inelastic processes of vibrationally 
excited molecules of hydrogen and its isotopes. Atom. Data Nucl. Data Tables 77 (2), 161-213.

Crompton, R.W., Elford, M.T., Jory, R.L., 1967. The momentum transfer cross section for electrons in helium. Aust. J. Phys. 20, 369-400, Phelps database $<$ www.lxcat.net> (retrieved 23.10.13).

Crompton, R.W., Gibson, D.K., McIntosh, A.I., 1969. The cross section for the $J=0 \rightarrow 2$ rotational excitation of hydrogen by slow electrons. Aust. J. Phys. 22, 715-732, Phelps database <www.lxcat.net> (retrieved 23.10.13).

Crompton, R.W., Elford, M.T., Robertson, A.G., 1970. The momentum transfer cross section for electrons in helium derived from drift velocities at $77 \mathrm{~K}$. Aust. J. Phys. 23, 667-682, Phelps database <www.lxcat.net> (retrieved on 23.10.2013).

Dyudina, U. et al., 2010. Detection of visible lightning on Saturn. Geophys. Res. Lett. 37, L09205.

Dyudina, U.A., Ingersoll, A.P., Ewald, S.P., Porco, C.C., Fischer, G., Yair, Y., 2013. Saturn's visible lightning, its radio emissions, and the structure of the 20092011 lightning storms. Icarus 226 (1), 1020-1037.

Farrell, W., Kaiser, M., Fischer, G., Zarka, P., Kurth, W., Gurnett, D., 2007. Are Saturn Electrostatic Discharges really superbolts? A temporal dilemma. Geophys. Res. Lett. 34 (6), L06202.

Festou, M.C., Atreya, S.K., 1982. Voyager ultraviolet stellar occultation measurements of the composition and thermal profiles of the saturnian upper atmosphere. Geophys. Res. Lett. 9, 1147-1150.

Fischer, G., Desch, M., Zarka, P., Kaiser, M., Gurnett, D., Kurth, W., Macher, W., Rucker, H., Lecacheux, A., Farrell, W., et al., 2006. Saturn lightning recorded by Cassini/RPWS in 2004. Icarus 183 (1), 135-152.

Fischer, G., Kurth, W., Dyudina, U., Kaiser, M., Zarka, P., Lecacheux, A., Ingersoll, A. Gurnett, D., 2007. Analysis of a giant lightning storm on Saturn. Icarus 190 (2), 528-544.

Fischer, G. et al., 2008. Atmospheric electricity at Saturn. Space Sci. Rev. 137 (1), 271-285.

Fischer, G. et al., 2011. A giant thunderstorm on Saturn. Nature 475 (7354), 75-77.

Galand, M., Moore, L., Charnay, B., Mueller-Wodarg, I., Mendillo, M., 2009. Solar primary and secondary ionization at Saturn. J. Geophys. Res. 114 (A6), A06313.

Gordillo-Vázquez, F.J., 2008. Air plasma kinetics under the influence of sprites. J. Phys. D: Appl. Phys. 41 (23), 234016.

Gordillo-Vázquez, F.J., 2010. Vibrational kinetics of air plasmas induced by sprites. J. Geophys. Res. (Space Phys.) 115 (A5), A00E25.

Hagelaar, G., Pitchford, L., 2005. Solving the Boltzmann equation to obtain electron transport coefficients and rate coefficients for fluid models. Plasma Sour. Sci. Technol. 14 (4), 722-733.

Hayashi, M., 1981. Report No. IPPJ-AM-19 1981. Institute of Plasma Physics, Nagoya University. Phelps database <www.lxcat.net> (retrieved 23.10.13).

Kuo, C.L., Chen, A.B., Chou, J.K., Tsai, L.Y., Hsu, R.R., Su, H.T., Frey, H.U., Mende, S.B., Takahashi, Y., Lee, L.C., 2008. Radiative emission and energy deposition in transient luminous events. J. Phys. D: Appl. Phys. 41 (23), 234014.

Kliore, A. et al., 2009. Midlatitude and high-latitude electron density profiles in the ionosphere of Saturn obtained by Cassini radio occultation observations. J. Geophys. Res. 114 (A4), A04315.

Li, C., Brok, W.J.M., Ebert, U., van der Mullen, J.J.A.M., 2007. Deviations from the local field approximation in negative streamer heads. J. Geophys. Res. 101, 123305.

Luque, A., Ebert, U., 2009. Emergence of sprite streamers from screening-ionization waves in the lower ionosphere. Nat. Geosci. 2, 757-760.
Luque, A., Gordillo-Vázquez, F.J., 2011. Mesospheric electric breakdown and delayed sprite ignition caused by electron detachment. Nat. Geosci. 5, 22-25.

Maggio, C., Marshall, T., Stolzenburg, M., 2009. Estimations of charge transferred and energy released by lightning flashes. J. Geophys. Res. 114, D14203.

Milloy, H.B., Crompton, R.W., 1977. Momentum-transfer cross section for electronhelium collisions in the range 4-12 eV. Phys. Rev. A 15, 1847-1850, Phelps database <www.lxcat.net> (retrieved 23.10.13).

Moore, L., Mendillo, M., Müller-Wodarg, I., Murr, D., 2004. Modeling of global variations and ring shadowing in Saturn's ionosphere. Icarus 172 (2), 503-520.

Moses, J., Bass, S., 2000. The effects of external material on the chemistry and structure of Saturn's ionosphere. J. Geophys. Res. 105 (E3), 7013-7052.

Nagy, A.F. et al., 2009. Upper atmosphere and ionosphere of Saturn. In: Saturn from Cassini-Huygens. Springer, p. 181.

Parra-Rojas, F.C., Luque, A., Gordillo-Vázquez, F.J., 2013. Chemical and electrical impact of lightning on the Earth mesosphere: The case of sprite halos. J. Geophys. Res. (Space Phys.) 118, 5190-5214.

Pasko, V.P., Stenbaek-Nielsen, H.C., 2002. Diffuse and streamer regions of sprites. Geophys. Res. Lett. 29 (10), 82.

Pasko, V.P., Inan, U.S., Bell, T.F., 1998. Spatial structure of sprites. Geophys. Res. Lett. 25 (12), 2123-2126.

Pasko, V.P., Yair, Y., Kuo, C.-L., 2012. Lightning related transient luminous events at high altitude in the Earth's atmosphere: Phenomenology, mechanisms and effects. Space Sci. Rev. 168 (1-4), 475-516.

Qin, J., Celestin, S., Pasko, V.P., 2011. On the inception of streamers from sprite halo events produced by lightning discharges with positive and negative polarity. J. Geophys. Res. (Space Phys.) 116, A06305.

Sánchez-Lavega, A. et al., 2011. Deep winds beneath Saturn's upper clouds from a seasonal long-lived planetary-scale storm. Nature 475 (7354), 71-74.

Sayanagi, K.M., Dyudina, U.A., Ewald, S.P., Fischer, G., Ingersoll, A.P., Kurth, W.S., Muro, G.D., Porco, C.C., West, R.A., 2013. Dynamics of Saturn's great storm of 2010-2011 from Cassini ISS and RPWS. Icarus 223 (460-478). http://dx.doi.org/ 10.1016/j.icarus.2012.12.013.

Sentman, D.D., 2004. Electrical breakdown parameters for neutral atmospheres of the Solar System. In: ISUAL Workshop Proceedings, 08-013-0016.

Sun, A.B., Teunissen, J., Ebert, U., 2013. Why isolated streamer discharges hardly exist above the breakdown field in atmospheric air. Geophys. Res. Lett. 40, 2417-2422. http://dx.doi.org/10.1002/grl.50457.

Thompson, R.T., Fowler, R.G., 1972. Lifetime and quenching rates for the $\mathrm{H}_{2}$ continuum. J. Quant. Spectrosc. Radiat. Trans. 12, 117-121.

Uman, M.A., 2001. The Lightning Discharge. Courier Dover Publications.

Wilson, C.T.R., 1925. The electric field of a thundercloud and some of its effects. Proc. Phys. Soc. London 37, 32D.

Yair, Y., 2012. New results on planetary lightning. Adv. Space Res. 50 (3), 293-310.

Yair, Y., Levin, Z., Tzivion, S., 1995. Lightning generation in a jovian thundercloud: Results from an axisymmetric numerical cloud model. Icarus 115 (2), 421-434.

Yair, Y., Takahashi, Y., Yaniv, R., Ebert, U., Goto, Y., 2009. A study of the possibility of sprites in the atmospheres of other planets. J. Geophys. Res. (Planets) 114, E09002.

Yoon, J. et al., 2008. Cross sections for electron collisions with hydrogen molecules. J. Phys. Chem. Ref. Data 37, 913-931, Itikawa database <www.lxcat.net> (retrieved 23.10.13). 